\title{
miRNAs associated with prostate cancer risk and progression
}

\author{
Hung N. Luu ${ }^{1,2}$, Hui-Yi Lin ${ }^{3}$, Karina Dalsgaard Sørensen ${ }^{4}$, Olorunseun O. Ogunwobi ${ }^{5}$, Nagi Kumar ${ }^{6}$, \\ Ganna Chornokur ${ }^{6}$, Catherine Phelan ${ }^{6}$, Dominique Jones ${ }^{7}$, LaCreis Kidd ${ }^{7}$, Jyotsna Batra ${ }^{8}$, Kosj Yamoah ${ }^{6,9}$, \\ Anders Berglund ${ }^{10}$, Robert J. Rounbehler ${ }^{11}$, Mihi Yang ${ }^{12}$, Sang Haak Lee ${ }^{13}$, Nahyeon Kang ${ }^{13}$, Seung Joon Kim ${ }^{13}$, \\ Jong Y. Park ${ }^{6 *}$ and Giuliano Di Pietro 6,14
}

\begin{abstract}
Prostate cancer is the most common malignancy among men in the US. Though considerable improvement in the diagnosis of prostate cancer has been achieved in the past decade, predicting disease outcome remains a major clinical challenge. Recent expression profiling studies in prostate cancer suggest microRNAs (miRNAs) may serve as potential biomarkers for prostate cancer risk and disease progression. miRNAs comprise a large family of about 22-nucleotide-long non-protein coding RNAs, regulate gene expression post-transcriptionally and participate in the regulation of numerous cellular processes. In this review, we discuss the current status of miRNA in studies evaluating the disease progression of prostate cancer. The discussion highlights key findings from previous studies, which reported the role of miRNAs in risk and progression of prostate cancer, providing an understanding of the influence of miRNA on prostate cancer. Our review indicates that somewhat consistent results exist between these studies and reports on several prostate cancer related miRNAs. Present promising candidates are miR-1, $-21,106 \mathrm{~b}$, $141,-145,-205,-221$, and -375 , which are the most frequently studied and seem to be the most promising for diagnosis and prognosis for prostate cancer. Nevertheless, the findings from previous studies suggest miRNAs may play an important role in the risk and progression of prostate cancer as promising biomarkers.
\end{abstract}

\section{Background}

Prostate cancer $(\mathrm{PCa})$ is the most common malignancy among men in the US. In 2016, there were approximately 180,890 new cases and 26,120 PCa related deaths [1]. Over the past two decades, PCa detection with serum prostate specific antigen (PSA/KLK3) has led to a significant increase in the detection of low-grade $\mathrm{PCa}$ (Gleason $<6$ ), a disease that has been shown to pose little risk of either metastatic spread or death. Active surveillance has thus evolved as a recommended management strategy for men with low grade disease. On the other hand, in 10 to $15 \%$ of cases, the cancer is aggressive and advances beyond the prostate, sometimes turning lethal, characterized by recurrence and early metastasis through the bloodstream and lymphatic system. Moreover, distant disease is associated with a

\footnotetext{
* Correspondence: Jong.Park@moffitt.org

${ }^{6}$ Department of Cancer Epidemiology, H. Lee Moffitt Cancer Center and Research Institute, Tampa, FL 33612, USA

Full list of author information is available at the end of the article
}

low 5-year survival rate of 28\% (2014-2015 ACS Cancer Treatment and Survivorship Facts and Figures). It should also be noted that racial differences may influence the diagnosis and also the progression and $\mathrm{PCa}$ treatment [2].

The most important clinical challenge is to distinguish men who have a potentially lethal form of $\mathrm{PCa}$ from those with an indolent disease [3]. Given the significant morbidity associated with treatment interventions, active surveillance could help identify men with aggressive disease who would benefit from intensive treatment compared to those in which conservative measures would suffice. Currently, the stratification of PCa patients is guided by the PSA kinetics, clinical stage, and the grade of tumor (Gleason score). Although these parameters are still clinically useful, they have limitations in detecting cases, predicting disease outcomes and guiding clinical management decisions. For example, the sensitivity of PSA with standard cut-off of $4 \mathrm{ng} / \mathrm{mL}$ is only $20.5 \%$ while the specificity is $93.6 \%$ [4]. Thus new biomarkers are 
urgently needed to improve existing diagnostic, prognostic and treatment management plans. Results from numerous reports suggest a critical role of microRNAs (miRNAs) in PCa progression (reviewed in [5]). These studies reveal expression of miRNAs are dysregulated in prostate tumor and indicated miRNAs may serve as promising PCa risk stratification biomarkers [5].

miRNAs comprise a large family of $~ 22$-nucleotidelong non-protein coding RNAs that regulate gene expression post-transcriptionally by both destabilizing mRNA transcripts and repressing their translation. Since the discovery of the first miRNA (lin-4) in 1993 [6], many other miRNAs have been identified [5, 7]. Reportedly, miRNAs normally regulate cellular processes such as development and differentiation in multicellular organisms $[8,9]$. Subsequent studies found that expression of miRNAs are significantly associated with various human cancers, including prostate cancer. For example, miR-143, miR-145, and miR-375 were identified as biomarkers with a high-level sensitivity and specificity in PCa detection [10], albeit unequivocally [5].

Most miRNAs bind at the 3' untranslated regions (3' UTR), 5' UTR and coding mRNA regions, which leads to mRNA degradation or translational inhibition [11-13]. miRNAs regulate the activity of more than $60 \%$ of all human gene products $[9,14,15]$. Biological functional studies suggest miRNAs are involved in the regulation a plethora of cellular processes, including those essential to tumorigenesis [14]. Each miRNA may regulate hundreds of genes with varying specificities through base pairing to mRNAs [16]. Moreover, a certain gene may serve as a targeted by multiple miRNAs via different binding sites $[17,18]$. Therefore, a miRNA can play a role in multiple biological cell signaling pathways by regulating the expressions and functions of their target genes [19]. Currently, there are over 1,800 human miRNAs identified. Many of them are expressed in a tissue-specific manner and changes in the expression of certain miRNAs are associated with various cancers including $\mathrm{PCa}$ (miRBase Release 21, www.mirbase.org) [14].

In this review, we will provide overview information on the current status of miRNA studies in PCa. The discussion will highlight key findings from human studies, examine the expression of miRNA in prostate tumor tissues with a view to understand the influence of miRNAs on prostate carcinogenesis or possibly the modulation of the clinical course of the disease. We will also review studies comparing the expression of miRNAs in different biological states of $\mathrm{PCa}$ via tumor tissue and biological fluid relative to controls. The review will conclude with a discussion of the therapeutic potential of miRNAs in $\mathrm{PCa}$ and on future directions of miRNA research in PCa.

\section{miRNA and prostate cancer}

miRNAs affect gene expression significantly and their dysregulation may cause tumorigenesis and its progression. The first report of miRNA's role in human cancer came from a study that characterized chromosome 13q14 in chronic lymphocytic leukemia (CLL) [20]. Since the first report of aberrant miRNA expression in CLL, the dysregulation of a number of miRNAs is closely associated with the development and progression of various cancers. Furthermore, about $50 \%$ of miRNA sequences are located in cancer-related regions (including fragile sites, breakpoint regions, viral integration sites and regions frequently linked with loss of heterozygosity or amplification) in the human genome, suggesting a role of miRNAs in cancer [21]. Moreover, recent studies indicated the dysregulation of miRNA profiles in $\mathrm{PCa}$ based on high-throughput methodologies (i.e., microarrays, RNA-Seq, proteomic arrays).

Further, miRNA expression profiles may help to distinguish between normal and tumor tissues [22-28]. miRNA profiles appear to have a better accuracy to differentiate between tumor and normal tissues when compared to mRNA profiling [29]. Expression profiles of miRNAs often correspond with clinic-pathological parameters and predict patient outcome or response to treatment [22, 30,31]. These observations underscore the potential of miRNAs as new diagnostic or prognostic biomarkers. Additionally, the oncogenic or tumorsuppressive functions of miRNAs [24, 32] suggested that miRNAs may be new candidates for cancer drug treatment. Beyond that, miRNAs has also been shown to be more stable than the mRNA and are therefore more suitable to be measured in formalin-fixed paraffin-embedded (FFPE) samples [33, 34]. The stability of miRNAs also makes miRNAs better candidates for blood-based markers [35, 36].

Dysregulation of miRNA in cancer could be caused by several genomic aberrations. These genomic anomalies may include, chromosomal modification, such as translocation, change of transcriptional factors and aberrant expression, epigenetic alterations, and changes in miRNA processing [22]. Several studies reveal miR155 is induced at the transcriptional level by transforming growth factor $\beta$ (TGFB1)/Smad, nuclear factor- $k \mathrm{~B}$ (NFKB1) and activator protein-1 (AP1) family transcription factors (JUN/JUNB/JUND/FOS/FOSB) through direct interaction with the miR-155 promoter [37-39].

\section{miRNAs as oncogenes and tumor suppressors}

miRNAs are divided into two types, oncogenes or tumor suppressors based upon whether their targets. Several miRNAs have been characterized as oncogenes and tumor suppressors in PCa. miRNAs inhibit the expression of tumor suppressor genes via their up-regulation 
in tumor cells, and are commonly termed oncogenic miRNAs or onco-miRs. The oncogenic miRNAs in PCa may enhance proliferative function by down-regulation of cell-cycle dependent kinase inhibitors p21 and p27 [40-42], as well as members of the E2F family of transcription factors [40, 43]. For example, miR-17-92 cluster contains six miRNAs (miR-17, -18a, -19a, -19b-1, $-20 \mathrm{a}$, and -92a-1) that are over-expressed in PCa [44], particularly miR-20a is over-expressed in prostate tumor tissues [45]. miR-20a decreases apoptosis in PCa PC-3 cells through repression of E2F2 and E2F3 and inhibition of miR-20a by antisense oligonucleotide, inducing the cell death [43]. Others PCa-associated onco-miRs, miR$1,-21,-106 \mathrm{~b},-125 \mathrm{~b},-221$ and -222 are known.

The expression of miR-1, also considered an oncomiRNA, is inversely related to the WDR6, XPO6 and SMARCA4 expression. However, miR-1 expression correlates positively with TWF1 transcription (PTK9) in PCa cells, suggesting that microRNAs binding may lead to mRNA cellular accumulation and sequestration of the inhibited mRNA. miR-1 also inhibit expression of exporter- 6 and protein tyrosine kinase 9 (also referred to as A6/twinfilin) in PCa cells [40]. Chang et al. [46] showed that decreased miR-1 levels was modulate by the activation of EGFR, leading to invasiveness and the involvement of TWIST1 in facilitating metastasis bone in PCa cell lines. These results indicated that EGFR functions as a transcription factor, repressing miR-1, which has an onco-suppressive role [46]. Kojima et al. [47] showed a down-regulation of miR-1, miR-15a, miR16-1, and miR-133a in PCa tissues, and these negative regulations contributed to the proliferation, migration and invasion in PC3 and DU145 cells. miR-1 and miR-133a may functioned as tumor suppressors that regulate PNP, an oncogenic gene in Pca [47]. Ambs et al. [40] and Martens-Uzunova et al. [48] observed downregulation in $\mathrm{PCa}$ tissues and linked to $\mathrm{PCa}$ progression, castration-resistant disease, and metastasis. Therefore, miR-1 was also suggested at candidate prognostic biomarker for Pca [46, 47, 49-53].

The miR-21 is overexpressed and plays an important role in $\mathrm{PCa}$ tumorigenesis, stimulating invasion and metastasis [45, 54-58], and induced invasion and motility of prostate tumor cells [59]. Ribas et al. [57] demonstrated androgen-induced Androgen Receptor binding to the miR-21 promoter that showed a direct transcriptional regulation, even after castration. Their results demonstrated that miR-21 contribute to $\mathrm{PCa}$ androgen receptor-driven proliferation and was overexpressed in LNCaP and LAPC-4 cells and in human tumors, but not correlate with stage, grade, or PSA [57]. The coordinated action of miR-21 and androgen receptor signaling, suppresses TGFBR2 levels through binding to its 3'UTR, enhancing androgen receptor signaling, thereby exerting its oncogenic effects on prostate tumors, through inhibition the suppressor activity of the tumor by TGF $\beta$ pathway [59]. The miR-21 may be implicated in the resistance to apoptosis, in motility and invasion in $\mathrm{PCa}$ cells [60]. miR-21 is able to downregulate Cyclin dependent kinase inhibitors expression by targeting the coding region of the gene, being able to attenuate the p57Kip2 action, which is inhibit the cell cycle [59]. An overexpressed miR-21 can lead to a decrease in the levels of RECK (Reversion-inducing cysteine-rich protein with Kazal motifs, a key inhibitor of several metaloproteinases) as well, and consequently cause an increase in the PCa promotion and progression [58].

miR-106b which targets the p21 (CDKN1A) and E2F1, displays an anti-apoptotic role in PCa cells by inhibiting caspase activation. Thus miR-106 suppressed E2F1 and p21/WAF1 protein expression [40]. Ambs et al. [40] and Szczyrba et al. [61] observed over-expression of miR-106b in gene expression profiling of prostate tumors. miR-106b appears to be a $\mathrm{PCa}$ oncogene, and was suggested as a candidate prognostic marker for $\mathrm{PCa}$ [62-64].

miR-125b is usually was over-expressed in androgenindependent $\mathrm{PCa}$ cells, but was downregulated in androgen-dependent LNCaP cells. Ectopic expression of miR-125b in LNCaP cells stimulates growth as a consequence of downregulation of its major target BAK1, a pro-apoptotic gene belonging to the Bcl-2 family [65, 66]. The miR-145 binds to the 3'UTR of MYO6 gene and regulated negatively, resulting in a decrease in myosin VI (involved in cancer-related cell migration), and $\beta$-actin in LNCaP cell line [61].

Poliseno et al. [62] has shown that miR-25, miR-93, and miR-106b are up-regulated in PCa and are inversely correlated with PTEN (phosphatase and tensin homolog deleted on chromosome 10, is a tumor suppressor that antagonizes signaling via the phosphatidylinositol-3kinase-Akt pathway) abundance in prostate cancer. The authors also observed that miR-22 transformed MEFs (mouse embryonic fibroblasts) when combined with cMYC (a regulatory gene encoding a transcription factor), as well as the miR-106b-25 cluster when combined with c-MYC or when combined with MCM7 (mini-chromosome maintenance protein 7). The expression of MCM7 correlated with tumor progression [62].

Hudson et al. [49] have observed that miR-32, miR106b-25, and miR-375 are up-regulated in primary tumor tissues and miR-106b-25 showed an additional increased in metastatic lesions especially in bones. On the other hand, miR-101 was down-regulated in tumors and metastases. The caspase- 7 , a novel candidate target of miR-106b-25, and its inhibition may be important in anti-apoptotic and oncogenic functions, promote cell cycle progression and hyper-proliferation, and miR- 
106b-25 can also alter the cell adhesion properties in PCa. miR-106b-25 negatively regulates Fas-activated kinase involved in apoptosis. The authors hypothesized that the combined inhibition of pro-apoptotic E2F1, Bim (apoptosis regulator), Fas-activated kinase (serine/threonine transferase kinase/transferase), caspase-7 and PTEN provides miR-106b-25 expressing in cancer cells. In addition, the down-regulation of cell death-inducing integrin-beta 8 , which is a target of miR-106b-25, and miR-93, can still support independent growth anchorage [49]. Liang et al. [64] have observed that REST (RE-1 Silencing Transcription Factor) expression decreases with overexpression of miR-93 and miR-106b-25 induced in LNCaP and PC3 cells hypoxia, and elevated expression of pro-neural Phox2a, as well the ASH-1 transcription factors and $\mathrm{TH}$ and ChgA NE markers. On the other hand, under conditions of hypoxia, excessive expression of miR-93 led to the destruction of REST [64].

The miR-200c also is upregulation, and it's targets with ZEB1 and ZEB2, that are transcription factors, that also are able to negatively regulate the miR-200c expression, thus increasing E-cadherin expression [61]. miR-205 has an onco-suppressive function by inhibiting the transition from epithelial to mesenchymal tissue, cell migration, and invasion in the human prostate [48]. Knockdown of miR-221 and miR-222, which are upregulated in the androgen-independent $\mathrm{PCa}$ cancer cell line, reduced the clonogenecity and tumorigenicity of androgen-independent PC-3 cells [41, 42]. Ectopic expression of miR-221 and miR-222 enhanced the colony forming potential and in vivo growth of androgen-dependent LNCaP cells by inducing a G1-S shift in the cell cycle [41].

In contrast to onco-miRs, tumor suppressor miRNAs were down-regulated in tumor cells to permit tumor progression. For example, the miR-15a/16-1 cluster located on chromosome 13q14 was frequently deleted in about $50 \%$ of PCa tumors [67]. Decreased activity of these two miRNAs resulted in hyperplasia of the prostate in mice and increased expression through intratumoral delivery resulted in the regression of PCa xenografts $[67,68]$. miR-15a-miR-16-1 cluster controlled cell survival, proliferation and invasion by suppressing cyclin D1 (CCND1) and WNT3A [67]. Similarly, miR-101 expression in $\mathrm{PCa}$ was decreased during progression of the disease mainly due to the loss of one or both of its genomic loci. Moreover, miR-101 inhibited the expression and function of EZH2, a member of the polycomb protein group [69].

The tumor-suppressive role of miRNAs in PCa has generally been ascribed to their ability to interfere with cell migration, invasion and pro-apoptotic functions. Ectopic expression of miR-126* significantly reduced the translation of prostein (SLC45A3), which is a prostatespecific protein involved in $\mathrm{PCa}$ motility and invasiveness. Presumably, miR-126 binds to the 3' UTR of prostein mRNA, resulted in reduced invasiveness of $\mathrm{LNCaP}$ cells [70]. Similarly, ectopic miR-34a expression induced cell cycle arrest and senescence, inhibited cell growth, and attenuated resistance to the chemotherapeutic agent camptothecin. miR-126 increased chemotherapy sensitivity by inducing apoptosis through suppression of the deacetylase sirtuin (SIRT1) and cyclin dependent kinase 6 (CDK6) and aggressive cellular behavior [71, 72].

Moreover, miR-146a reduced cell proliferation, invasion and metastasis of PC-3 cells to human bone marrow endothelial cell monolayers through the suppression of the Rho-associated protein kinase ROCK1 [73]. Other tumor suppressor-associated miRNAs evaluated in $\mathrm{PCa}$ cell models included miR-23b, miR-145, and miR-205. Ectopic expression of miR-23b, and miR-145 in LNCaP cells significantly reduced proliferation [74-77]. Similarly, ectopic expression of miR-205 in PCa cells resulted in reduction of cell locomotion and invasion and downregulation of several oncogenes involved in PCa progression [78].

Although functional studies might define certain miRNAs as onco-miRNAs or tumor suppressor miRNAs, their expression in prostate tumors might not correlate with these classifications. For instance, miR-125b, miR221, miR-222, miR-373 and miR-520c as onco-miRs in experimental models [41, 42, 65, 66]; however, these miRs were down-regulated in prostate tumor tissue relative to normal prostate tissue [76, 79-81]. miR-373 and miR-520c play a critical role in $\mathrm{PCa}$ by inhibiting expression of CD44 RNA [82]. Other miRNAs also defied their given classification as either a tumor suppressor or oncogenic miRNAs. Previous functional studies demonstrated a dual role for miRs-133b and -375 in different PCa cell lines [83-85].

Normally, miR-133b is downregulated as a tumor suppressor miR and miR-375 is upregulated as an oncomiR in PCa tumor tissue relative to normal tissue. However, forced expression of miR-133b increased proliferation in androgen-dependent cells (LNCaP, 22Rv1) [84] while miR-375 decreased proliferation and invasion of androgen-independent PC-3 cells [85]. Thus functional studies performed in experimental models might not perfectly recapitulate clinical disease [86]. In the same way, miR-373 was 1.5 times more prevalent in benign glandular and benign stromal cells, than in the same tissues from PCa patients, as well as miR-520c showed reduced in primary tumors and metastases. Never the less, miR-373 and miR-520c act as pro-invasive agents, mediated by binding with CD44 3'UTR [82].

In summary, miRNAs have an important role in human cancer. More than $50 \%$ of miRNA genes are 
located in cancer-associated regions in the human genome and the expressions of miRNAs are dysregulated in various human cancers, including PCa. Certain miRNAs are upregulated in cancer (onco-miRs), while others are downregulated (tumor suppressors). However, expression profiles and functional studies of miRNAs in $\mathrm{PCa}$ cell lines do not always correlate with expression in prostate tumor tissue.

\section{miRNAs in prostate cancer}

Numerous biomarkers have been proposed as promising predictors for risk and/or progression of PCa. However, most biomarkers could not clearly demonstrate their independent clinical potential and, therefore, these biomarkers fail to enhance accuracy of current nomograms. Since the first discovery of miRNAs [6] in 1993, many studies have investigated whether dysregulation of miRNA expression in $\mathrm{PCa}$ may correlate with the risk and progression of this disease. These studies reported a number of differentially expressed miRNAs in biological samples from patients with PCa. Tables 1 and 2 summarize results from studies of miRNA expression in $\mathrm{PCa}$.

\section{Diagnosis/progression of prostate cancer based on tissue} MicroRNA profiling in PCa tissues shows different expression patterns as compared with normal tissues. These unique miRNA expression profiling may provide tools for better prediction of diagnosis and progression of PCa. These data also assist to determine treatment strategies of PCa.

Porkka et al. [87] reported that differential expression of 51 miRNAs between $\mathrm{BPH}$ and prostate tumor tissues based on data from oligonucleotide array hybridization. Eight of these miRNAs were upregulated, while 22 were down-regulated in tumor tissues as compared with ones in $\mathrm{BPH}$ tissues. The authors observed an expression of several miRNAs, Let-7f, miR-19b, -184 , and -198 , were associated with advanced disease. Ambs et al. [40] evaluated mRNAs profiles detected in 60 LCM prostate tumors and 16 non-tumor prostate tissues using genome-wide expression assays. Expression of some miRNAs was significantly different comparing prostate tumors and non-tumor samples (miR-32, -133a-1, -490, $-494,-520 \mathrm{~h}$ ) as well as patients with organ-confined PCa vs. extra prostatic disease extension (miR-101-1/2, $-200 \mathrm{a}$, and -200b). These data suggested that miRNA dysregulation was related to development and progression of PCa. Further, the mRNA and miRNA analyses revealed influence the expression of cancer related genes by miRNAs in PCa cells. For example, the miR-106b-25 cluster maps to intron 13 of MCM7, which was significantly up-regulated in prostate tumors [40].
Ozen et al. [79] analyzed the expression of 480 human miRNAs between 10 benign peripheral zone tissues and 16 prostate tumors using microarrays and observed and validated down-regulation of several miRNAs including let-7c, miR-125b, and miR-145 in localized prostate tumor samples compared to benign peripheral zone tissue, and demonstrated miR-145 expression has a heterogeneous pattern in PCa tissue [79]. Mercateli et al. [42] showed overexpression of miR-221 is sufficient to strongly induce growth of LNCaP xenografts in mice. The tumor growth advantage in miR-221 expressing was significantly higher than mice in the referent group $(p=0.01)$. The average volume fold increase of miR-221 expressing tumors was higher than control tumors $(p=0.025)$ [42].

With high-throughput liquid phase hybridization (mirMASA) reactions and 114 miRNA probes, Tong et al. [76] observed downregulation of miR-221 and other miRNAs (miR-23b, $-100,-145$, and -222) in malignant prostate tissue $(n=40)$. They developed the 48 miRNA signature (including miR-135b and miR-194) that predicted biochemical recurrence after prostatectomy. Further evidence was provided for the growth modulatory roles of miRNAs by showing reduced ectopic expression of miR-23b, $-145,-221$ and -222 in LNCaP cell [76]. Khan et al. [88] analyzed over 1,000 proteins with multidimensional liquid phase peptide fractionation followed by tandem mass spectrometry, using 15 tissues samples, 5 of the prostate tumor, 5 of adjacent benign tissue and 5 of distant metastatic tissues. The study revealed the involvement of $\mathrm{miR}-128-\mathrm{a} / \mathrm{b}$ in regulating progression of $\mathrm{PCa}$, where the miR-128 levels were elevated in lines of $\mathrm{BPH}$ prostatic epithelial cells, when compared to invasive $\mathrm{PCa}$ cells. The findings were validated in an independent set of 15 clinical specimens. Furthermore, transient overexpression of miR-128 in PCa cell lines attenuated cellular invasion, which suggest miR-128 as an important negative regulator of cellular invasiveness in vitro [88].

Prueitt et al. [80] showed a role of miRNAs in PCa progression by demonstrating a higher expression of 19 miRNAs (particularly miR-224) and downregulation of 34 miRNAs (particularly metallothioneins and proteins with mitochondrial localization and involvement in cell metabolism) in patients with progression than those with a locally confined disease [80]. However, Kristensen et al. [89] reported epigenetic downregulation of miR224 and miR-452 (which are located in an intron of the GABRE) was a significant independent adverse predictor for time to BCR after radical prostatectomy in two large PCa patient cohorts ( $n=293$ and 198, respectively) [89]. Wang et al. [90] analyzed about 273 miRNAs using cell lines from $62 \mathrm{PCa}$ patients with aggressive phenotype (Gleason score $\geq 8$ ) and 63 PCa patients with nonaggressive 
Table 1 Summary of miRNA expression studies on samples from prostate cancer patients

\begin{tabular}{|c|c|c|c|}
\hline Author year (reference) & Tissue/serum & Outcome & miRNA identified \\
\hline \multicolumn{4}{|l|}{ Risk/Diagnostic } \\
\hline Ozen, 2008 [79] & Tissue & Risk/Diagnostic & Let-7b-g, 26a-b, 29a-c, 30a-e, 99a-b, 125a-b \\
\hline Gandellini, 2009 [78] & Tissue & Risk/Diagnostic & miR-205 \\
\hline Mahn 2011 [118] & Tissue/Serum & Diagnostic & let7i, 16, 26a, 195 \\
\hline Wach, 2012 [10] & Tissue & Diagnostic & miR-143, 145, 375 \\
\hline Avgeris, 2013 [101] & Tissue & Diagnostic & miR-145 \\
\hline Srivastava, 2013 [105] & Tissue/Urine & Diagnostic & miR-205, 221, 99b \\
\hline Tsuchiyama, 2013 [106] & Tissue & Diagnostic & miR-182-5p \\
\hline Guzel 2015 [107] & Tissue & Diagnostic & miR-361-3p, 133b, 221, 203 \\
\hline Roberts, 2015 [128] & Tissue/Serum & Diagnostic & miR-200b, 200c, 375 \\
\hline Kristensen 2016 [112] & Tissue & Diagnostic & $\begin{array}{l}\text { Up: miR-375, 663b, 615-3p, 425-5p, 663a, 182-5p, 183-5p. } \\
\text { Down: miR-205-5p, 221-3p, 222-3p, 376c-3p, 136-5p, 455-3p, } \\
\text { 455-5p, }-154-5 p\end{array}$ \\
\hline Mitchell, 2008 [35] & Serum & Diagnostic & miR-141 \\
\hline Lodes, 2009 [137] & Serum & Diagnostic & miR-16, 92a, 103, 107 \\
\hline Moltzahn, 2011 [99] & Serum & Diagnostic & miR-26b, 223, 874, 1274a \\
\hline Yaman Agaoglu, 2011 [54] & Plasma & Diagnostic & miR-21, 141, 221 \\
\hline Selth, 2012 [114] & Serum & Diagnostic & miR-141, 298, 346, 375 \\
\hline Chen 2012 [119] & Plasma & Diagnostic & let7c, let7e, 30c, 622, 1285 \\
\hline Cheng, 2013 [120] & Serum & Diagnostic & miR-210 \\
\hline Haldrup, 2014 [113] & Serum & Diagnostic & miR-141, 375 \\
\hline Westermann, 2014 [121] & Serum & Diagnostic & miR-141 \\
\hline Kachakova, 2015 [122] & Plasma & Diagnostic & let-7c, 375 \\
\hline Haj-Ahmad, 2014 [126] & Urine & Diagnostic & miR-182-5, 484 \\
\hline Korzeniewski, 2014 [127] & Urine & Diagnostic & miR-483-5p, 1275, 1290 \\
\hline \multicolumn{4}{|l|}{ Risk/Progression } \\
\hline Porkka, 2007 [87] & Tissue & Risk/Progression & Let-7a-d, Let-7f, 19b, 145, 184, 198, 202, 210, \\
\hline Ambs, $2008[40]$ & Tissue & Risk/Progression & miR-1, 32, 101, 106b, 182, 200a, 200b, 494, 520 h \\
\hline Mercatelli, 2008 [42] & Tissue & Progression & miR-221, 222 \\
\hline Prueitt, 2008 [80] & Tissue & Progression & miR-2, 10, 125b, 224 \\
\hline Tong, 2009 [76] & Tissue & Risk/Progression & miR-23b, 100, 135b, 145, 194, 221, 222 \\
\hline Wang, 2009 [90] & Tissue & Progression & miR-9*, 16, 221, 222, 331-3p, 145, 551a \\
\hline Szczyrba, 2010 [61] & Tissue & Progression & miR-143 \\
\hline Shaefer, 2010 [81] & Tissue & Risk/Progression & miR-96, 205 \\
\hline Pesta, 2010 [93] & Tissue & Progression & miR-20a \\
\hline Khan, 2010 [88] & Tissue & Progression & miR-128 \\
\hline Spahn, 2010 [91] & Tissue & Progression & $\operatorname{miR}-221$ \\
\hline Hagman, 2010 [92] & Tissue & Risk/Progression & miR-34c \\
\hline Brase, 2011 [115] & Tissue/Serum & Progression & miR-141, 375 \\
\hline Barnabas, 2011 [103] & Tissue & Progression & miR-151 \\
\hline Leite, 2011 [138] & Tissue & Progression & let7c, miR-100, miR-145, miR-191 \\
\hline Martens-Uzunova, 2012 [48] & Tissue & Progression & miR-1, 133a, 133b, 143, 143*, 145, 145*, 204, 221, 222 \\
\hline Li, 2012 [55] & Tissue & Progression & miR-21 \\
\hline Tsuchiyama, 2013 [106] & Tissue & Progression & miR-182-5p \\
\hline Amankwah, 2013 [102] & Tissue & Progression & miR-21 \\
\hline
\end{tabular}


Table 1 Summary of miRNA expression studies on samples from prostate cancer patients (Continued)

\begin{tabular}{|c|c|c|c|}
\hline He, 2013 [134] & Tissue & Progression & miR-19a, miR-374b \\
\hline Kristensen, 2014 [89] & Tissue & Progression & miR-224, 452 \\
\hline Wang, 2014 [124] & Tissue/Serum & Progression & miR-19, miR-345, miR-519c-5p \\
\hline Dip, 2015 [139] & Tissue & Progression & Let-7c \\
\hline Zhang, 2011 [100] & Serum & Progression & miR-21 \\
\hline Yaman Agaoglu, 2011 [54] & Plasma & Progression & miR-21, miR-221 \\
\hline Shen, 2012 [56] & Plasma & Progression & miR-20a, miR-21, miR-145, miR-221 \\
\hline Watahiki, 2013 [123] & Plasma & Progression & $\operatorname{miR}-21,-126,-141,-151-3 p,-152,-200 c,-375,-423-3 p$ \\
\hline Nguyen, 2013 [116] & Serum & Progression & miR-141, miR-375, miR-378, miR-409-3p \\
\hline \multicolumn{4}{|l|}{ Diagnostic/Progression } \\
\hline Hao, 2011 [95] & Tissue & Diagnostic/Progression & miR-21 \\
\hline Mihelich, 2011 [98] & Tissue & Diagnostic/Progression & miR-96, miR-182, miR-183 \\
\hline Bryant 2012 [117] & Serum/Urine & Diagnostic/Progression & $\begin{array}{l}\text { miR-181a-2, miR-625, miR-107, miR-574-3p, miR-20a, } \\
\text { miR-23a, miR-624 }\end{array}$ \\
\hline Mavridis, 2013 [109] & Tissue & Diagnostic/Progression & miR-224 \\
\hline Larne, 2013 [108] & Tissue & Diagnostic/Progression & miR-96-5p, miR-183-5p, miR-145-5p, miR-221-5p \\
\hline Walter, 2013 [110] & Tissue & Diagnostic/Progression & $\begin{array}{l}\text { Up: miR-122, miR-335, miR-184, miR-193, miR-34, miR-138, } \\
\text { Down: miR-373, -9, -198, -144-215, -96, -222, -148, } \\
-92,-27,-125,-126,-27\end{array}$ \\
\hline Casanova-Salas, 2014 [111] & Tissue/Serum & Diagnostic/Progression & miR-187 and miR-182 \\
\hline Mihelich, 2015 [125] & Serum & Diagnostic/Progression & $\begin{array}{l}\text { let-7a, }-24,-26 b,-30 c,-93,-100,-103,-106 a,-107 \\
-130 b,-146 a,-223,-451,-874\end{array}$ \\
\hline Kristensen, 2016 [112] & Tissue & Diagnostic/Progression & miR185-5p, miR-221-3p, miR-326 \\
\hline \multicolumn{4}{|l|}{ Treatment response } \\
\hline $\mathrm{He}, 2013$ [134] & Tissue & Treatment Response & miR-23b, miR-220, miR-221, miR-222, and miR-205 \\
\hline Lichner, 2013 [135] & Tissue & Treatment Response & miR-152 \\
\hline Gonzales, 2011 [133] & Plasma & Treatment Response & miR-141 \\
\hline Cheng, 2013 [120] & Serum & Treatment Response & miR-210 \\
\hline Someya, 2015 [136] & Blood & Treatment Response & miR-99a \\
\hline
\end{tabular}

phenotype (Gleason grade $\leq 5$ ) and identified a significant association with PCa grade in 7 miRNAs included miR-16, $-9 *-145,222,-221,-331-3 p$, and $-551 a$, especially the miR-145 and miR-331-3p, showed significantly downregulated in aggressive $\mathrm{PCa}$ [90].

Schaefer et al. [81] analyzed tumor tissue and normal adjacent tissue from two groups of 76 and 79 men with untreated PCa. This study demonstrated miR-130b with a significantly different expression between normal and tumor tissues. miRs-125b, -205 and -222 were significantly related to tumor stage while miRs-31, -96 and -205 showed a significant correlations with Gleason score. When the combination of six miRNAs (miR-96, $-149,-181 b,-182,-205$ and -375) was used, the AUC was significant (0.88) in discriminating normal and tumor tissue [81]. Spahn et al. [91] analyzed samples from $\mathrm{BPH}$, primary $\mathrm{PCa}$ of a high risk group and corresponding metastatic tissues by microarray analysis. A PCa specific miRNA expression signature was generated based on the differential expression of 66 (48 downregulated and 18 upregulated) miRNAs between tumor and $\mathrm{BPH}$ tissues $(p<0.01)$. They observed a progressive downregulation of miR-221 in aggressive and metastatic PCa. Downregulation of miR-221 was also associated with Gleason score and clinical recurrence [91].

Hagman et al. [92] found the relative expression of miR-34c was significantly lower in the PCa samples compared to the $\mathrm{BPH}$ samples $(p=0.0005)$ and decreased with higher grade. The miR-34c level in patients with metastasis was found to be significantly lower than patients without metastasis $(p=0.02)$. The expression of miR-34c distinguishes aggressive from non-aggressive PCa $(p=0.012)$ and was inversely correlated with PSA level. Although there was no significant correlation between miR-34c expression levels and treatment/ response to treatment, the expression of miR-34c was significantly correlated with survival [92]. 
Table 2 Summary of miRNA expression studies on prostate tumor/serum samples

\begin{tabular}{|c|c|c|c|}
\hline miRNA investigated & Expression & Tissue & Reference \\
\hline $\begin{array}{l}\text { let-7a-2,let-7i,16-1,17-5p,20a,21,24-1,25,27a,29a,29b-2,30c,32, 34a,92-2,93-1, } \\
95,101-1,106 a, 124 a-1,126 a-1,135-2,146,149,181 b-1,184,187,191,196-1 \text { 197, } \\
\text { 199a-1, 214,128a, 195,198, 199a-1,199a-2,203,206,214,218-2,223, }\end{array}$ & up & tumor & Volina, 2006 [45] \\
\hline $202,210,296,320,370,373^{*}, 498,503$ & up & tumor & Porkka, 2007 [87] \\
\hline $\begin{array}{l}\text { let-7i,25,26a-1/2,31,32,34b,92-1/2,93,99b,106b,125a,181a-1/2,182, } \\
188,194-1 / 2,196 a / 2,200 c, 370,375,425,449\end{array}$ & up & tumor & Ambs, 2008 [40] \\
\hline 221,222 & up & tumor & Mercatelli, 2008 [42] \\
\hline $16,19 b, 24,100,125 b, 141,143,296$ & up & serum & Mitchell, 2008 [35] \\
\hline $141,200 b, 200 c$ & up & prostate cells & Mitchell, 2008 [35] \\
\hline 221 & up & PCa cells & Mercatelli, 2008 [42] \\
\hline 221 & up & tumor & Spahn, 2009 [91] \\
\hline $9^{*}, 15 a, 16,145,221,222,331,551 a$ & up & PCa cells & Wang, 2009 [90] \\
\hline 128 & up & PCa cells & Khan, 2010 [88] \\
\hline let-7a,let-7c,let-7f,15b,20a,21,25,26b,30b,106a, 106b, 126*,148a,200c,218,375, & up & tumor & Szczyrba, 2010 [61] \\
\hline $25,93,106 b$ & up & tumor & Poliseno, 2010 [61] \\
\hline $96,182,182^{*}, 183$ & up & tumor & Schaefer, 2010 [81] \\
\hline 141 & up & plasma & Gonzales, 2011 [133] \\
\hline 182 & up & Prostate cells & Mihelich, 2011 [98] \\
\hline 100,145,191,let7c & up & tumor & Leite, 2011 [138] \\
\hline $9^{*}, 141,200 b, 375,516 a-3 p$ & up & serum & Brase, 2011 [115] \\
\hline 21 & up & plasma & Yaman Agaoglu, 2011 [54] \\
\hline $34 c$ & up & PCa cells & Hao, 2011 [95] \\
\hline $20 a, 21,221$ & up & plasma & Shen, 2012 [56] \\
\hline $107,141,301 a, 326,432,484,574-3 p, 625^{*}, 2110$ & up & plasma & Bryant, 2012 [117] \\
\hline 21 & up & tumor & Li, 2012 [55] \\
\hline $\begin{array}{l}\text { let-7b,7, } 9^{*}, 17,19 b, 20 a, 21,25,30 d, 32,92 a-1 *, 93,95,96,106 a^{*}, 106 b, 106 b^{*}, 130 b, \\
142-3 p, 141^{*}, 148 a, 153,182,182^{*}, 183,183^{*}, 200 b^{*}, 200 c^{*}, 210,301 b, 363,375 \\
425,512-3 p, 583,615-3 p, 663,801\end{array}$ & up & tumor & Martens-Uzunova, 2012 [48] \\
\hline let-7a,20a,21,106a,106b,375, & up & tumor & Wach, 2012 [10] \\
\hline $96,124,141,302 b, 375,378^{*}, 489,520 d-5 p, 548 a-3 p, 548 c-3 p, 875-5 p, 892 b$, & up & serum & Nguyen, 2013 [116] \\
\hline $96-5 p, 183-3 p, 183-5 p$ & up & tumor & Larne, 2013 [108] \\
\hline $\begin{array}{l}\text { 10b,15a,15b,16,18a,18b,20b,25,30c,32,34a,34c-5p, 92a, 122, 124,125a-5p, } \\
\text { 125b,128a,133b, 134, 135b,146b-5p,148b,181a,181b,181c,184,193a-5p, } \\
\text { 193b,206,214, 215,301a,372 }\end{array}$ & up & tumor & Walter, 2013 [110] \\
\hline 19a, 188-5p,574-5p,663,939,1224-5p,1225-5p,1249,1915,K12-3,UL70-3p, & up & tumor & $\mathrm{He}, 2013$ [134] \\
\hline 21 & up & tumor & Amankwah, 2013 [102] \\
\hline $32,106 b-25,375$ & up & tumor & Hudson, 2013 [53] \\
\hline $96-5 p, 182-5 p, 183-5 p$ & up & tumor & Tsuchiyama, 2013 [106] \\
\hline $141,200 a, 200 c, 210,375$ & up & serum & Cheng, 2013 [120] \\
\hline $\begin{array}{l}\text { 19a,19b,20a,20b,26a,26b,29c,106a,125a,125b,135a, 141, 148a,151-5p,174b, } \\
\text { 193a, 196b, 331-3p,365, 374a, 374b, 1274b, }\end{array}$ & up & tumor & Lichner, 2013 [135] \\
\hline $19 b$ & up & tumor & Wang, 2014 [124] \\
\hline 182,SNORD78,U17b,U78_s,U78_x & up & tumor & Casanova-Salas 2014 [111] \\
\hline $17^{*}, 200 b^{*}, 210,297,375,501-3 p, 551 b, 562$ & up & serum & Haldrup, 2014 [113] \\
\hline $345,519 c-5 p$ & up & serum & Wang, 2014 [124] \\
\hline $93,106 b-25$ & up & PCa cells & Liang, 2014 [61] \\
\hline Let-7a, $103,107,130 b, 106 a, 26 b, 451,223,93,24,30 c, 874,100,146 a$ & up & serum & Mihelich, 2015 [125] \\
\hline
\end{tabular}


Table 2 Summary of miRNA expression studies on prostate tumor/serum samples (Continued)

\begin{tabular}{|c|c|c|c|}
\hline $\begin{array}{l}\text { let-7a-5p,let-7d-3p,let-7d-5p,7-5p,7b-5p,20a-5p,21-3p,25-3p, 29b-2-5p,30d-3p, } \\
\text { 92a-3p, 92b-3p, 93-3p,96-5p,103a-3p,107, 130b-3p, 182-5p,183-5p,191-5p, } \\
\text { 196b-5p,200b-3p, 200b-5p, 200c-3p 329, 331-3p,339-3p,342-5p,375,421, } \\
\text { 423-3p,423-5p, 425-5p, 484, 615-3p,663a,663b,664a-3p, 1248,1260a }\end{array}$ & up & tumor & Kristensen, 2016 [112] \\
\hline $\begin{array}{l}\text { Let-7a,let-7b,let-7c,let-7d,let-7 g,16,23a,23b,26a,92,99a,103,125a,125b,143, } \\
145,195,199 a, 199 a^{*}, 221,222,497\end{array}$ & down & tumor & Porkka, 2007 [87] \\
\hline $\begin{array}{l}\text { let-7b,1-2,34a,145,7-1/2,126,128a,133a-1,145,205,218-2,220,221,329,340,345, } \\
410,487,490,494,499,520 \mathrm{~h}\end{array}$ & down & tumor & Ambs, $2008[40]$ \\
\hline let-7b-g, 26a-b,29a-c,30a-e,99a-b,125a-b,145, 200a-b & down & tumor & Ozen, 2008 [79] \\
\hline $\begin{array}{l}\text { 22,24,27a,27b,29a,30e, 101,125a-5p,125b,143, 145, 152, 199a-5p,221,223, } \\
320,424,\end{array}$ & down & tumor & Szczyrba, 2010 [61] \\
\hline $16,31,125 b, 145,149,181 b, 184,205,221,222$ & down & tumor & Schaefer, 2010 [81] \\
\hline $34 c$ & down & tumor & Hagman, 2010 [92] \\
\hline $34 c$ & down & PCa cells & Hao, 2011 [95] \\
\hline $30 c, 100,223,346$ & down & Prostate cells & Mihelich, 2011 [98] \\
\hline 141 & down & plasma & Yaman Agaoglu, 2011 [54] \\
\hline $143,145,221$ & down & tumor & Wach, 2012 [10] \\
\hline $1,15 a, 16-1,133 a$ & down & tumor & Kojima, 2012 [52] \\
\hline $\begin{array}{l}1,10 b, 27 b, 29 a, 29 b, 34 b, 126,126^{*}, 130 a, 133 a, 133 b, 139-5 p, 142-3 p, 142-5 p, 143, \\
143^{*}, 145,145^{*}, 146 a, 149,150,155,181 b, 193 b, 193 b^{*}, 204,205,221,221^{*}, 222,223, \\
224,328,338-3 p, 342-5 p, 361-3 p 378,378^{*}, 455-3 p, 455-5 p, 483-3 p, 485-3 p, 551 b\end{array}$ & down & tumor & Martens-Uzunova, 2012 [48] \\
\hline $181 a-2^{*}$ & down & plasma & Bryant, 2012 [117] \\
\hline $31-5 p, 34 c-5 p, 205-5 p, 221-3 p, 222-3 p$ & down & tumor & Tsuchiyama, 2013 [106] \\
\hline 101 & down & tumor & Hudson, 2013 [49] \\
\hline 221,222 & down & tumor & Amankwah, 2013 [102] \\
\hline $\begin{array}{l}23 b, 26 b, 30 c, 155,181 d, 193 a-5 p, 200 b-5 p, 205,221,221-5 p, 222,224,335,374 a \\
374 b, 455-3 p, 505\end{array}$ & down & tumor & $\mathrm{He}, 2013$ [134] \\
\hline $145-5 p, 205-5 p, 221-5 p, 409-5 p$ & down & tumor & Larne, 2013 [108] \\
\hline 224 & down & tumor & Mavridis, 2013 [109] \\
\hline 222 & down & serum & Cheng, 2013 [120] \\
\hline 409-3p,623, & down & serum & Nguyen, 2013 [116] \\
\hline $19 a, 19 b$ & down & serum & Wang, 2014 [124] \\
\hline $34 a^{*}, 34 c-3 p, 187,221^{*}, 221,224$ & down & tumor & Casanova-Salas 2014 [111] \\
\hline $1,133 b$ & down & tumor & Karatas, 2014 [55] \\
\hline 1 & down & Prostate cells & Chang, 2015 [46] \\
\hline $\begin{array}{l}15 a-5 p, 16-5 p, 19 b-3 p, 22-3 p, 23 a-3 p, 23 b-3 p, 24-3 p, 26 a-5 p, 27 a-3 p, 27 b-3 p, \\
29 a-3 p, 29 b-3 p, 30 a-3 p, 30 a-5 p, 30 c-5 p, 30 e-3 p, 30 e-5 p, 33 a-5 p, 34 a-5 p, 99 a-3 p \\
99 a-5 p, 101-3 p, 125 b-2-3 p, 125 b-5 p, 127-3 p, 130 a-3 p, 132-3 p, 136-5 p, 143-3 p \\
149-5 p, 152,154-5 p, 155-5 p, 181 a-5 p, 181 b-5 p, 195-5 p, 199 a-3 p, 199 a-5 p, 199 b-5 p, \\
205-5 p, 214-5 p, 218-5 p, 221-3 p, 222-3 p, 223-3 p, 335-5 p, 338-3 p, 362-3 p \\
363-3 p 376 a-3 p, 376 c-3 p, 424-5 p, 451 a, 455-3 p, 455-5 p, 497-5 p, 502-3 p, 660-5 p\end{array}$ & down & tumor & Kristensen, 2016 [112] \\
\hline
\end{tabular}

Pesta et al. [93] evaluated the expression of four miRNAs, miR- let-7a, $-15 \mathrm{a},-16$, and $20 \mathrm{a}$ in 53 prostate tumor and 85 benign prostatic hyperplasia $(\mathrm{BPH})$ tissues to investigate whether miRNA expression is related to clinic-pathological features of PCa. They observed a difference in expression for miR-20a in patients with a Gleason score of 7-10 compared with patients with a low Gleason score of less than 6, suggesting an oncogenic role for miR-20a in PCa development [93].
Although the previous study demonstrated the potential of miR-20a to distinguish between more and less aggressive $\mathrm{PCa}$ disease, the use of $\mathrm{BPH}$ tissue is not the most appropriate control relative to normal tissue and potentially impede the identification of unique miRNAs in PCa. On the other hand, Taylor et al. [94] reported that, the copy-number alterations in prostate tumors modestly revealed distinct subgroups with substantial differences in time to biochemical recurrence while 
unsupervised hierarchical clustering of mRNA and miRNA data failed to identify robust clusters of patients with significant differences in prognosis [94].

Szczyrba et al. [61] found 16 miRNAs upregulated by at least 1.5 -fold and 17 miRNAs downregulated by at least 1.5 -fold in snap frozen prostate tumor tissue. Strong upregulation was found for miR-148a, -200c, -375 , and the miR-143, -145 and -223 were downregulated [61]. In another study by Hao et al. [95], miR-21, and miR-141 were upregulated at least 2-fold, while miR-10, $-16,-34 \mathrm{c}$, and $-125 \mathrm{~b}$, were downregulated in formalin fixed paraffin embedded (FFPE) tumor tissues as compared with BPH specimens [95]. The positive predictive value was enhanced from 40 to $87.5 \%$ when the PSA variable was added with expression variable of miR21 and miR-141. After analysis of tumor samples from Caucasians and African-Americans, miR-182 level tended to be higher in PCa tissues and miR-30c, -100 , -223 , and -346 were expressed at lower levels in $\mathrm{PCa}$ tissue in Caucasians.

Therefore, miR-21 may indicate a potential role of carcinogenesis in prostate tissue [57]. In addition, multiple studies reported that miR-21 is an oncogene in prostate cancer and over-expression may be related to the development of castration-resistance PCa [57-60, 96]. In addition, Bonci et al. [97] recently reported overexpression in $\mathrm{PCa}$ metastasis.

A RNA microarray profiling analysis of a patient cohort with organ-confined prostate tumors indicated the overexpression of miR-96, -182 , and -183 with at least 2-fold in laser captured micro-dissected (LCM) PCa tissue compared with normal adjacent prostate tissue [98]. Moltzahn et al. [99] identified miRNA signatures which can distinguish healthy controls from patients and correlate with a prognosis. Cluster and ROC analyses indicated the diagnostic potential and the ability to further separate $\mathrm{PCa}$ patients according to their risk of recurrence by their miRNA signatures [99]. Zhang et al. [100] assessed a potential role of serum miR-21 in the progression of $\mathrm{PCa}$ with 56 patients, including 20 localized $\mathrm{PCa}, 20$ with androgen-dependent PCa (ADPC), 10 with hormone-refractory PCa (HRPC), and 6 with BPH. Significantly higher levels of miR-21 were detected in patients with ADPC and HRPC, especially in those resistant to docetaxel-based chemotherapy. These findings suggest miR-21 may be a biomarker at the transition to hormone refractory disease and a potential indicator for response to treatment in PCa patients [100].

Martens-Uzunova et al. [48] analyzed the expression of miRNAs in 102 prostate tumor tissues, adjacent normal tissues, lymph and trans-urethral resection from normal and PCa patients. Regarding the miRNAs, the authors analyzed 80 miRNA species, where 22 were identified with significant differences between the two groups with or without $\mathrm{PCa}$ that can serve as a diagnosis markers. The authors also identified a miR profile consist of 25 miRNAs, which 12 overexpressed and 13 under-expressed in prostate tumor tissues with poor outcome. This 25 miRNA profile is very accurate to predict a recurrence (AUC $=0.991, p<0.0001$ Kaplan-Meier analysis). They also observed that the overall expression of miRNA was lower in PCa malignant lymphoma compared to the PCa prostate tissues. 19 miRNAs have been upregulated in metastatic lymph node while 69 miRNAs, including miR-1, $-133 \mathrm{a},-133 \mathrm{~b},-143,-143^{*},-145$, $-145^{*},-204,-221$ and -222 , have been downregulated in comparison to PCa tissue [48].

Li et al. [55] confirmed the miR-21 expression in 169 PCa tissue samples was significantly associated with clinical variables, such as stage, lymph node involvement, capsular invasion, organ confined disease, Gleason score, BCR and patient follow-up. The relationship between miR-21 as BCR persisted even after adjusting for standard clinico-pathological parameters (i.e., PSA, patient age, Gleason score, surgical margin, lymph node metastasis, capsular invasion, and pathological stage) [55].

Avgeris et al. [101] evaluated the clinical utility of miR-145 using 137 prostate tumor tissues and 64 benign samples. They found that the reduction of miR-145 expression in PCa was correlated with Gleason score, clinical stage, tumor size and PSA level and follow-up PSA levels. Further, the reduction of miR-145 expression was significantly associated with increased risk for biochemical recurrence and shorter disease-free survival (DFS) among PCa patients. This relationship remained significant after adjusting for Gleason score, clinical stage, PSA and age at diagnosis [101]. We [102], reported a significantly increased risk for recurrence $(p<0.0001)$ in patients with decreased expression of miR-21, but not for miR-221 $(p=0.57)$ or miR-222 $(p=0.24)$. An increased risk of recurrence was more prominent in obese $(p=0.031)$ than non-obese patients. After adjustment for stage and Gleason score, the results showed miR-21 expression was independently linked to disease recurrence among obese patients [102].

Barnabas et al. [103] observed a copy number gain of miR-151 gene at 8q24 in PCa tissues from AfricanAmerican men who developed BCR after radical prostatectomy. These data suggested a copy number gain of miR-151 gene in primary tumor that may indicate the presence of metastatic disease [103]. Leite et al. [104] observed a 2.7-3.4 fold higher likelihood of BCR when miR-100, $-145,-191$, and let-7c were over-expressed. However, only miR-100 showed a significant association independently with BCR in multi-variable analysis [104].

Srivastava et al. [105] evaluated expression of $8 \mathrm{miR}$ NAs in 40 paired prostate tissues. miR-205, miR-214, 
miR-221 and miR-99b were significantly downregulated in PCa tumor tissue. These miRNA profiles can discriminate $\mathrm{PCa}$ patients from healthy individuals successfully [105]. Tsuchiyama et al. [106] tested whether levels of miRNAs were correlated with aggressiveness. Expression of miR-315p, -34c-5p, and -205-5p was significantly decreased compared to those in normal tissues regardless of Gleason pattern $(p<0.05)$. Meanwhile, in the same patients with high grade $\mathrm{PCa}$, expression of miR-31-5p $-182-5 p$, and $-205-5 p$ in tumor tissues was higher than ones obtained from intermediate Gleason tumor $(p<$ 0.05 ) [106]. Using prostate tissues from $23 \mathrm{PCa}$ and 25 BPH patients from Turkey, 4 candidate miRNAs were evaluated (i.e., miR-133b, $-203,-221$, and $-361-3 p$ ). miR-361-3p was significantly lower in tumor tissues from PCa than BPH patients $(p=0.004)$. Both miR-133b and miR-221 were downregulated in PCa compared to BPH ( $p<0.01$ and 0.03 , respectively). The levels of miR203 were found to be significantly upregulated in $\mathrm{PCa}$ samples $(p=0.0002)$. The AUC values of all miRNAs, miR-133b, miR-203, miR-221, and miR-361-3p were $0.73,0.81,0.71$, and 0.74 , respectively [107].

Larne et al. [108] developed a formula which can predict early stage of PCa with aggressive progression characteristics. Using differentially expressed miRNAs in PCa tissue samples, the authors developed a miRNA signature, consisting of four miRNAs [(miR-96-5p x miR183-5p)/(miR-145-5p x miR221-5p)], denoted as the miRNA index quote (miQ). The miQ provided an excellent diagnostic discrimination. The median of miQ is 17 times higher in the $\mathrm{PCa}$ group compared to the nonPCa group $(p<0.0001)$. Further, miQ level is also associated with grades $(p=0.0067)$, PSA levels $(p<0.0001)$, metastasis $(p<0.0001)$ and survival $(p=0.0014)$. More importantly, miQ distinguishes aggressive tumors from non-aggressive $\mathrm{PCa}(p<0.0001)$ with an AUC of 0.90 (95\% CI: 0.77-0.97) [108].

Mavridis et al. [109] reported that miR-224 could distinguish PCa patients from $\mathrm{BPH}$ patients with an AUC of $0.67(p=0.001)$ in tissue samples. miR-224 expression inversely correlated with aggressiveness $(p=0.017)$, thus Gleason score, advanced disease stage, PSA, risk of relapse and positively with progression-free survival [109]. Walter et al. [110] found upregulation of miR-143 and miR-146b and loss of 18 miRNAs (e.g. miR-34c, $-29 \mathrm{~b}$, -212 and $-10 \mathrm{~b})$ in the PCa tumors relative to normal epithelium and/or stroma $(p<0.001)$. In addition, upregulation of 11 miRNAs and downregulation of 7 miRNAs were found in the tumors with high Gleason score $(\geq 8)$ when compared with ones with Gleason score 6 [110]. Casanova-Salas et al. [111] found the expression miR182 was increased in PCa tissue samples and decreased 6 miRNAs, miR-34a*, $-34 \mathrm{c}-3 \mathrm{p},-187,-221^{*},-221$ and. 224. Further miR-182 and miR-187 were also differentially expressed according to clinical variables, such as Gleason score, stage, status of TMPRSS2-ERG and progression [111].

In one of the largest miRNA profiling studies published for PCa, Kristensen et al. [112] analyzed the expression of 752 miRNAs in a training set of 13 nonmalignant and $134 \mathrm{PCa}$ tissue samples. Subsequently, a total of 93 miRNAs with diagnostic/prognostic potential were selected for further validation in two similar-sized independent patient cohorts. The authors identified several novel deregulated miRNAs in PCa as compared to nonmalignant prostate tissue samples as well as between more/less aggressive PCa subgroups, as defined by clinic-pathological parameters. Most notably, the authors also identified a novel 3-miRNA prognostic signature (miR-185-5p + miR-221-3p + miR-326) predicted time to biochemical recurrence after radical prostatectomy independently of routine clinical variables in a training cohort as well as in two independent validation cohorts. This is the first report to demonstrate independent prognostic value for a miRNA signature in three independent $\mathrm{PCa}$ patient cohorts, supporting the potential clinical relevance of this signature [112].

\section{Diagnosis/progression of prostate cancer based on serum} Some studies have examined the differential expression of miRNAs in serum or plasma in an attempt to develop a blood based diagnosis, detection of progression and recurrence of PCa. Mitchell et al. [35] showed that serum levels of miR-141 can distinguish $\mathrm{PCa}$ patients from healthy controls, supporting the potential role of this miRNA as a diagnostic marker for PCa. The upregulation of miR-141 in PCa patients was confirmed in later studies [54, 95, 113-117]. Mahn et al. [118] found circulating oncogenic miRNAs (i.e., miR-26a, $-32,-195$ and let-7i), particularly miR-26a have a sensitivity of $89 \%$ and specificity of $56 \%$ (area under the curve: $\mathrm{AUC}=$ $0.70)$ for diagnosis. The diagnostic accuracy increased when these four miRNAs were analyzed in combination (sensitivity: 78.4\%, specificity: 66.7\%, AUC = 076). Increased levels of miR-16, $-26 a$, and -195 were inversely associated with surgical margin positivity. miR-195 and -let7i were also inversely associated with Gleason score. They found a significant reduction of miR-16, -26a, and -195 levels after radical prostatectomy. miR-32 was found to be down-regulated in $\mathrm{PCa}$ tissue $(p=0.02)$ [118].

Chen et al. [119] found that a panel of five serum miRNAs (let-7c, let-7e, miR-30c, -622 and -1285) were significantly different in $\mathrm{PCa}$ patients as compared to healthy controls in both identification and validation cohorts. All 5 miRNAs could distinguish $\mathrm{PCa}$ from healthy controls individually. The respective sensitivity and specificity values were: let-7c, 68.5 and $70 \%$; let-7e, 
77.8 and 75\%; miR-30c, 79.6 and $68.8 \%$; miR- 622, 90 and 63.0\%; miR-1285, 61.3 and 57.4\% [119]. Wach et al. [10] reported on the detection of miR-145 in endothelial cells of blood vessels but not stromal cells. Based upon the ratio of miRNA expression, they concluded that miR-145 may be the best negative predictive biomarker suitable for diagnostic or prognostic purposes in PCa [10].

Selth et al. [114] used a mouse model of PCa as a tool to discover serum miRNAs that could be used in a clinical setting. Among 45 miRNAs identified, four miRNAs (miR-141, -298, -346, and -375) were significantly elevated in metastatic PCa samples as compared to those in healthy controls (all $p<0.05$ ). miR-141 and miR-375 were associated with biochemical recurrence (BCR) [114]. Cheng et al. [120] identified five serum miRNAs (miR-141, -200a, -200c, -210, and -375) associated with metastatic castration resistant $\mathrm{PCa}$ in both screening and validation cohorts. In the screening cohort, serum levels of five miRNAs were significantly increased in $\mathrm{PCa}$ cases as compared with controls (miR-141: $p<0.0001, \mathrm{AUC}=0.90 ; \mathrm{miR}-200 \mathrm{a}: p=0.007$, AUC $=0.70 ;$ miR-200c: $p=0.017, \quad$ AUC $=0.72 ; \quad \mathrm{miR}-$ 210: $p=0.02, \quad \mathrm{AUC}=0.68$; and miR-375: $p=0.009$, AUC $=0.77$ ), while the respective $\mathrm{p}$-values of these five miRNAs were $0.001,0.073,0.055,0.022$, and 0.021 in a validation cohort [120].

Haldrup et al. [113] performed genome-wide miRNA profiling of serum samples from $13 \mathrm{BPH}$ control and 31 PCa patients. The dysregulation of miR-141 and -375 , two of the most well-documented candidate miRNA markers for PCa, was confirmed. Further, they developed three novel and highly specific miRNA panels (miR$562 /-210 /-501-3 p /-375 /-551 b$ ) able to identify $84 \%$ of all PCa patients, $80 \%$ of patients with disseminated $\mathrm{PCa}$ (let-7a*/miR-210/-562/-616), and $75 \%$ of disseminated PCa patients when compared to localized PC patients (miR-375/-708/-1203/-200a) [113]. miR-141 levels were significantly increased in patients with a higher Gleason score $(p=0.05)$ although the levels of miR-26a-1 and -141 in 170 pre-biopsy serum samples were similar in patients with positive and negative biopsies $(p=0.72$, $\mathrm{AUC}=0.52$ and $p=0.84, \mathrm{AUC}=0.49$, respectively) [121]

The expression levels of 4 miRNAs in plasma from 59 PCa patients with different clinic-pathological characteristics and two groups of controls, $16 \mathrm{BPH}$ samples and 11 young asymptomatic men (YAM) were analyzed to evaluate their diagnostic and prognostic value in comparison to PSA. miR-375 was significantly downregulated in $83.5 \%$ of patients compared to $\mathrm{BPH}$ controls and showed stronger diagnostic accuracy $(\mathrm{AUC}=0.81$, 95\% CI: $0.70-0.92, p=0.00016)$ compared with PSA (AUC $=0.71,95 \%$ CI: $0.56-0.86, p=0.013$ ). Sensitivity of $86.8 \%$ and specificity of $81.8 \%$ were reached when all biomarkers were combined $(\mathrm{AUC}=0.88)$ and YAM were used as calibrators [122].

In a study of $51 \mathrm{PCa}$ patients and 20 healthy controls in Turkey, Yaman Agaoglu et al. [54] investigated the levels of miRs-21, -141 , and -221 in plasma of patients and healthy controls. They found miR-21 and miR-221 levels were significantly higher in prostate patients than controls $(p<0.001, \quad$ ROC-AUC $=88 \%$ and $p<0.001$, AUC $=83 \%$; respectively), but not for miR-141 $(p=0.20)$. miR-141, however, was found to be significantly higher in local advanced patients in comparison with those diagnosed with local outcome $(p<0.001$, AUC $=76 \%)$ [54]. Brase et al. [115] observed enhanced expression of miR-375 and miR-141 in prostate tumor tissue compared to normal tissue and both miRNAs were upregulated in the sera of patients with metastatic disease compared to those with localized disease and correlated with high Gleason score or lymph-node positive status. These findings show miR-375 and miR-141 detection in serum may be associated with advanced disease [115].

Nguyen et al. [116] demonstrated over-expression miR-375, -378, and -141 were significantly in serum collected from castration resistant $\mathrm{PCa}$ patients compared to those with localized disease, while miR-409-3p was significantly under-expressed. In prostate tumor tissues, the expression of miR-375 and miR-141 were significantly higher than those in normal prostate tissue [116]. Relative to normal tissue, miR-205 (downregulated in $\mathrm{mCRPC}$ ) was indicated by Watahiki et al. [123] to be associated with a lower Gleason score and a lower probability of both BCR and clinically evident metastatic events after prostatectomy. To the contrary, miR-141, 151-3p, 152 and 423-3p are inversely associated with prognosis and/or Gleason score. miR-141 and -152 may identify individuals with a high probability of recurrence after surgical treatment. miR-423-3p and miR-205 were suggested as novel prognostic factors due to their correlation with several clinical parameters [123].

Wang et al. [124] investigated whether pre-surgical serum levels of miRNAs can identify PCa patients. miR19a and miR-19b displayed higher expression in the case group compared to controls, consistent with higher serum levels in cases. Conversely, miR-345 and $-519 c-5 p$ had significantly lower expression among PCa patient. These results were consistent with lower levels in the patients' serum samples. Logistic regression models for predicting case/control status showed all four miRNAs as highly significant predictors of outcome status even when controlling for age, PSA, clinical stage, and degree of biopsy involvement. In the validation cohort, expression data of 4 miRNAs were consistent with data from the discovery cohort. Models consisting of a combination either miR-19a or $-19 b$ together with miR-345 and 
- 519c-5p showed an AUC of 0.94, reaching high significance ( $p=0.02$ and $p=0.017$ respectively) [124].

Shen et al. [56] also found miR-20a, -21 and -145 levels were significantly associated with $\mathrm{PCa}$ but not disease aggressiveness. The combination of these three miRNAs was a significant predictor and distinguished high risk PCa patients [56]. Martens-Uzunova et al. [48] evaluated some miRNAs significantly different in lymphocytes that could be used in the evaluation of progression of $\mathrm{PCa}$, although some demonstrated an upregulation 2 fold-change or more between normal and $\mathrm{PCa}$ tissue (miR- 95, 96, 32, 153,182, 182*, 183) were and others (miR-133a, 133b, 221, 221* 222, 224, 338-3p, $378^{*}, 455-5 \mathrm{p}$ ) were downregulation, especially miR-205 showed 6.3 fold downregulation [48]. Karatas et al., studying tissue samples from patients with recurrent and non-recurrent $\mathrm{PCa}$, confirmed a negative uptake of miR1 and miR-133b, miR-145* in recurrent Pca [51].

Mihelich et al. [125] developed the equation, miR Risk Score based on 7 miRNAs, miR, let-7a, -26b, -106a, $-107,-130 \mathrm{~b},-223$, and -451 in plasma samples. This scoring system showed to be highly predictive of lowgrade PCa. The AUC for low-grade PCa was 0.69 across the range of miR risk scores [125]. Bryant et al. [117] reported 12 miRNAs were differentially expressed in $\mathrm{PCa}$ patients plasma compared with controls. Among the 12 miRNAs, 11 were significantly correlated with metastases. The association of two miRNAs, miR-141 and miR375 with metastatic PCa was confirmed in a separate cohort. An analysis of urine samples indicated miR-107 and miR-574-3p were significantly associated with $\mathrm{PCa}$ risk [117].

\section{Diagnosis/progression of prostate cancer based on urine and ejaculation}

Srivastava et al. evaluated expression of 8 miRNAs in urine and tissue samples. miR-205, and miR-214 were significantly downregulated in PCa patients in both tissue and urine specimens. This miRNA profile can discriminate $\mathrm{PCa}$ patients from healthy individuals with $89 \%$ sensitivity and $80 \%$ specificity [105]. Haj-Ahmad et al. [126] performed miRNA expression profiling with urine samples obtained from $8 \mathrm{PCa}$ patients, $12 \mathrm{BPH}$ patients and 10 healthy males using whole genome expression analysis. Differential expression of two individual miRNAs between healthy males and BPH patients was detected and found to possibly target genes related to $\mathrm{PCa}$ development and progression among $894 \mathrm{miR}$ NAs assayed. The authors found the sensitivity and specificity of miR-1825 for detecting $\mathrm{PCa}$ among $\mathrm{BPH}$ individuals were 60 and 69\%, respectively. Further, the sensitivity and specificity for miR-1825 and -484 using tandem deregulation at the same time were 45 and $75 \%$, respectively [126]. Another urine study suggested miR- 483-5p was significantly associated with PCa based on samples from $71 \mathrm{PCa}$ patients and 18 controls $(p=0.01$; $\mathrm{AUC}=0.69)$ [127].

Roberts et al. [128] evaluated the diagnostic performance of ejaculated-derived PCA3, Hepsin, and miRNAs (miR-125b, -200b, -200c, and -375) in 61 $\mathrm{PCa}$ patients. In stratified analysis, miR-200c (AUC $=$ $0.79)$ and miR-375 (AUC $=0.76)$ demonstrated as the best single marker performance, while a combination of serum PSA, miR-200c and miR-125b further improved a prediction capacity for PCa status as compared to PSA alone determined by biopsy (AUC = 0.87 vs. $0.67 ; p<0.05$ ), and prostatectomy pathology $(\mathrm{AUC}=0.81$ vs. 0.70$)$. For PCa status by biopsy, the specificity enhanced from $11 \%$ for PSA only to $67 \%$ for a combination of PSA, miR-200c, and miR-125b, with $90 \%$ specificity [128].

miRNA as predictors of therapeutic response for prostate cancer

miRNAs affect the expression of multiple genes in disease pathways and therefore represent interesting drug targets. Different experimental approaches used to validate the function of miRNAs can be potentially developed for miRNA-based therapies. For example, over-expressed oncogenic miRNAs can efficiently be inhibited using modified antisense oligonucleotides and this strategy was positively evaluated in animal models [129-131]. Expression of down-regulated tumor suppressor miRNA can be restored using synthetic precursor double stranded miRNA molecules or miRNA expression vectors delivered through lentiviral systems $[67,86]$. miRNAs can also be exploited to increase the sensitivity of tumor cells to conventional anticancer agents [86]. For example, identification of miRNAs involved in the transition from androgen-independent to androgen-dependent state will aid in the modulation of the androgen-independent phenotype with the aim of increasing the responsiveness of advanced $\mathrm{PCa}$ to anticancer therapies. Some studies have currently demonstrated miRNAs are differentially expressed in androgen-independent compared to androgen-dependent PCa cell lines $[65,66,73,132]$.

With Low-Density Arrays (TLDA) to screen differentially expressed serum miRNAs, Cheng et al. [120] found that serum level of miR-210 were correlated with PSA level change per day during treatment $(p=0.029)$. Furthermore, expression of miR-210 was significantly lower in non-aggressive disease patients, as compared to those with recurrence $(p=0.001)$. The authors suggest that a subset of mCRPC patients may have a higher hypoxia response signaling, leading to increased miR-210 and therapy resistance. These data suggested miR-210 levels could be used to identify a distinct, subset of mCRPC 
patients with tumor-associated hypoxia. Gonzales et al. [133] studied in 21 PCa patients in a longitudinal manner with multiple blood draws. They determined the levels of miR-141 in PCa patients and compared it to the levels of three other conventional PCa biomarkers: PSA, lactate dehydrogenase (LDH) and circulating tumor cells (CTC). Then they found that miR-141 level changes were similar with changes observed by PSA, $\mathrm{LDH}$ and CTC and to the clinical assessments of the patients, suggests miR-141 can be used as a marker for therapeutic response in $\mathrm{PCa}$ patients. He et al. [134] reported that 28 miRNAs were differentially expressed between PCa tumor and adjacent benign tissues. The authors compared the miRNA expression profiles to non-Chinese populations and found that miR-23b, -220 , $-221,-222$, and -205 may be common targets for treatments in all populations. This study also identified 15 specific miRNAs in Chinese patients. miR-374b and miR-19a showed significant correlations with clinicalpathological features in Chinese patients [134].

Lichnew et al. [135] confirmed results for 2 miRNAs were downregulation of miR-331-3p $(p=0.009)$ in the low-risk BCR group and miR-152 in the high-risk group $(p=0.012)$. To further confirm their results, using a second independent set of PCa cases, they observed similar results, as expected. The prediction model correctly classified high-risk individuals $(33 / 35,94.3 \%)$ and low-risk individuals $(6 / 29,20.7 \%)$ [135]. Someya et al. [136] investigated an association between miRNA expression and radio-sensitivity of $\mathrm{PCa}$ patients. They observed different miRNA expression among $\mathrm{PCa}$ patients with different radiation treatments. Three miRNAs (miR-99a, -147 and -508) in non-irradiated peripheral blood lymphocytes (PBLs) and one miRNA in irradiated PBLs (miR-199b), and significant induction of 11 miRNAs by irradiation (miR- 28, -185, -221, -340, -376c, -422a, $-486,-491,-542,-652$ and -660$)$ were found. The authors concluded a combination of low ATPdependent DNA helicase II (Ku80/XRCC5) expression and highly-induced miR-99a expression could be a promising marker for predicting radio-sensitivity after radiotherapy [136].

\section{Conclusions}

miRNAs regulate gene expression post-transcriptionally by both destabilizing mRNA and inhibiting their translation. Post-transcriptional regulation guarantees rapid and reversible changes in protein synthesis without altering transcription. Further, miRNAs can simultaneously modulate several cancer-relevant gene networks, because of their ability to bind to several targets. These attributes make miRNAs attractive candidates relevant as one-hit multi-target (polypharmacological) therapeutic agents against $\mathrm{PCa}$ and cancer in general. Further, miRNAs represent a potential source of $\mathrm{PCa}$ diagnostic biomarkers. The stability of miRNA in serum and plasma and previous work showing differential expression of serum miRNA in normal and tumor tissue suggest the potential of miRNA as blood-based biomarkers for PCa diagnosis.

However, detailed knowledge of their expression, regulation, target genes and mechanism of action is required to achieve this goal. Moreover, it is critical to establish standard protocols for miRNA normalization and collection of tissue biospecimens. Some studies analyze miRNA expression in laser micro-dissected tumor tissue to procure tumor tissue with high purity $[40,98,105$, 106]. Unfortunately, other studies continue to analyze miRNA expression in snap frozen or FFPE tissue as observed in this review $[61,95,101]$. RNA endogenous controls (e.g., RNU44, RNU6B) can vary from study to study. The analysis of miRNA expression in non-microdissected tumor tissue and use of various miRNA endogenous controls, may skew miRNA expression profiles in PCa. For biological fluids (i.e., serum, plasma, urine), there is no designated endogenous control to normalization miRNA expression in cancer. However, some studies utilize stable synthetic Caenorhabditis elegans (i.e., Cel-39, -54, -238) as spike-in internal controls to normalized miRNA expression in serum $[35,115]$. It is well known that African American men are 2.5 times more likely to die from PCa relative to Caucasian men [1]. In this review, majority of the miRNA profiling studies utilized pre-dominantly Caucasian populations. Given this apparent racial disparity in $\mathrm{PCa}$, more miRNA profiling studies in diverse populations are needed to identify ethnic-specific miRNAs that may possibly play a role in aggressive disease among African American men. Ultimately, miRNA profiling in tumor tissue and biological fluids collected from more diverse populations using more standardized miRNA normalization protocols may lead to the identification of more key miRNAs and elucidate the role of miRNAs in $\mathrm{PCa}$ disease prevalence in certain populations.

Further studies in in vivo knockout or knock-in models should be helpful in understanding the pathways affected by miRNAs. Further, gene expression and proteomic analysis associated with loss- and gain-of-function studies in different model systems might contribute to a better understanding of the cellular networks affected by miRNA in the development and progression of cancer [5]. Additional investigation is also warranted to ascertain whether dysregulation of miRNA expression is causative rather than a consequence of cancer.

In summary, expression profiling studies provide evidence for the role of miRNAs in PCa diagnosis and prognosis. However, limited overlap exists between these studies and an extremely limited number of PCa-related 
miRNAs are currently known. Present promising candidates are miR-1, -21, 106b, 141, miR-145, miR-205, miR-221, and miR-375, which are the most frequently studied and seem to be the most promising for diagnosis and prognosis for prostate cancer.

\section{Acknowledgment}

This research was supported in part, by the National Cancer Institute grant R01CA128813 (PI: Park, JY)

\section{Competing interests}

The authors declare that they have no competing interests.

\section{Authors' contributions}

$H L, G D, J P$ carried our the literature search and drafted the manuscript. $H L$, $K S, O O, N K, G C, C P, D J, L K, J B, K Y, A B, R R, M Y, S L, N K$, SK participated in the design of the study and revision. All authors read and approved the final manuscript.

\section{Publisher's Note}

Springer Nature remains neutral with regard to jurisdictional claims in published maps and institutional affiliations.

\section{Author details}

'Division of Epidemiology, Department of Medicine, Vanderbilt Epidemiology Center, Vanderbilt-Ingram Cancer Center, Vanderbilt University School of Medicine, Nashville, TN, USA. ${ }^{2}$ Department of Epidemiology and Biostatistics, College of Public Health, University of South Florida, Tampa, FL, USA. ${ }^{3}$ Biostatistics Program, School of Public Health, Louisiana State University Health Sciences Center, New Orleans, LA 70112, USA. ${ }^{4}$ Department of Molecular Medicine, Aarhus University Hospital, Aarhus, Denmark. ${ }^{5}$ Department of Biological Sciences, Hunter College of The City University of New York, New York, NY 10065, USA. ${ }^{6}$ Department of Cancer Epidemiology, H. Lee Moffitt Cancer Center and Research Institute, Tampa, FL 33612, USA. ${ }^{7}$ Department of Pharmacology and Toxicology, James Brown Cancer Center, University of Louisville School of Medicine, Louisville, KY 40202, USA. ${ }^{8}$ Australian Prostate Cancer Research Centre-QLD, Institute of Health and Biomedical Innovation and School of Biomedical Sciences, Translational Research Institute, Queensland University of Technology, Brisbane, Australia. ${ }^{9}$ Department of Radiation Oncology, H. Lee Moffitt Cancer Center and Research Institute, Tampa, FL 33612, USA. ${ }^{10}$ Department of Biostatistics and Bioinformatics, H. Lee Moffitt Cancer Center and Research Institute, Tampa, FL 33612, USA. "'Department of Tumor Biology, H. Lee Moffitt Cancer Center and Research Institute, Tampa, FL 33612, USA. ${ }^{12}$ Research Center for Cell Fate Control, College of Pharmacy, Sookmyoung Women's University, Seoul, Republic of Korea. ${ }^{13}$ Department of Internal Medicine, The Cancer Research Institute, College of Medicine, The Catholic University of Korea, Seoul, Republic of Korea. ${ }^{14}$ Department of Pharmacy, Federal University of Sergipe, Rodovia Marechal Rodon, Jardim Rosa Elze, Sao Cristóvão, Brazil.

Received: 14 September 2016 Accepted: 2 March 2017

Published online: 20 March 2017

\section{References}

1. Siegel RL, Miller KD, Jemal A. Cancer statistics, 2016. CA Cancer J Clin. 2016; 66(1):7-30.

2. Pietro GD, Chornokur G, Kumar NB, Davis C, Park JY. Racial differences in the diagnosis and treatment of prostate cancer. Int Neurourol J. 2016;20 Suppl 2:S112-9.

3. Shen MM, Abate-Shen C. Molecular genetics of prostate cancer: new prospects for old challenges. Genes Dev. 2010;24(18):1967-2000.

4. Ankerst DP, Thompson IM. Sensitivity and specificity of prostate-specific antigen for prostate cancer detection with high rates of biopsy verification. Arch Ital Urol Androl. 2006;78(4):125-9.

5. Amankwah EaP, JY. miRNAs in human prostate cancer. In: Toxicology and epigenetics. edn. Edited by Sahu S. Chichester: The Wiley; 2012. p. 205-17.

6. Lee RC, Feinbaum RL, Ambros V. The C. elegans heterochronic gene lin-4 encodes small RNAs with antisense complementarity to lin-14. Cell. 1993; 75(5):843-54.
7. Bentwich I. Prediction and validation of microRNAs and their targets. FEBS Lett. 2005;579(26):5904-10.

8. Wahid F, Shehzad A, Khan T, Kim YY. MicroRNAs: synthesis, mechanism, function, and recent clinical trials. Biochim Biophys Acta. 2010;1803(11):1231-43.

9. Wienholds $E$, Plasterk RH. MicroRNA function in animal development. FEBS Lett. 2005:579(26):5911-22.

10. Wach S, Nolte E, Szczyrba J, Stohr R, Hartmann A, Orntoft T, Dyrskjot L, Eltze E, Wieland W, Keck B, et al. MicroRNA profiles of prostate carcinoma detected by multiplatform microRNA screening. Int J Cancer. 2012;130(3):611-21.

11. Bartel DP, Chen CZ. Micromanagers of gene expression: the potentially widespread influence of metazoan microRNAs. Nat Rev Genet. 2004;5(5):396-400.

12. Pang Y, Young CY, Yuan H. MicroRNAs and prostate cancer. Acta Biochim Biophys Sin Shanghai. 2010;42(6):363-9.

13. Rigoutsos I. New tricks for animal microRNAS: targeting of amino acid coding regions at conserved and nonconserved sites. Cancer Res. 2009;69(8):3245-8.

14. Krol J, Loedige I, Filipowicz W. The widespread regulation of microRNA biogenesis, function and decay. Nat Rev Genet. 2010;11(9): 597-610.

15. Friedman RC, Farh KK, Burge CB, Bartel DP. Most mammalian mRNAs are conserved targets of microRNAs. Genome Res. 2009;19(1):92-105.

16. Schaefer A, Jung M, Kristiansen G, Lein M, Schrader M, Miller K, Stephan C, Jung K. MicroRNAs and cancer: current state and future perspectives in urologic oncology. Urol Oncol. 2010;28(1):4-13.

17. Brennecke J, Stark A, Russell RB, Cohen SM. Principles of microRNA-target recognition. PLoS Biol. 2005;3(3):e85.

18. Filipowicz W, Bhattacharyya SN, Sonenberg N. Mechanisms of posttranscriptional regulation by microRNAs: are the answers in sight? Nat Rev Genet. 2008;9(2):102-14.

19. Santarpia L, Nicoloso M, Calin GA. MicroRNAs: a complex regulatory network drives the acquisition of malignant cell phenotype. Endocr Relat Cancer. 2010;17(1):F51-75

20. Calin GA, Dumitru CD, Shimizu M, Bichi R, Zupo S, Noch E, Aldler H, Rattan $S$, Keating M, Rai K, et al. Frequent deletions and down-regulation of microRNA genes miR15 and miR16 at 13q14 in chronic lymphocytic leukemia. Proc Natl Acad Sci U S A. 2002;99(24):15524-9.

21. Zhang B, Pan $X$, Cobb GP, Anderson TA. microRNAs as oncogenes and tumor suppressors. Dev Biol. 2007;302(1):1-12.

22. Calin GA, Croce CM. MicroRNA signatures in human cancers. Nat Rev Cancer. 2006;6(11):857-66.

23. Calin GA, Croce CM. MicroRNAs and chromosomal abnormalities in cancer cells. Oncogene. 2006;25(46):6202-10.

24. Calin GA, Croce CM. MicroRNA-cancer connection: the beginning of a new tale. Cancer Res. 2006;66(15):7390-4.

25. Cummins JM, Velculescu VE. Implications of micro-RNA profiling for cancer diagnosis. Oncogene. 2006;25(46):6220-7.

26. Dalmay T. MicroRNAs and cancer. J Intern Med. 2008;263(4):366-75.

27. Dalmay T, Edwards DR. MicroRNAs and the hallmarks of cancer. Oncogene. 2006;25(46):6170-5.

28. Tricoli JV, Jacobson JW. MicroRNA: potential for cancer detection, diagnosis, and prognosis. Cancer Res. 2007;67(10):4553-5.

29. Lu J, Getz G, Miska EA, Alvarez-Saavedra E, Lamb J, Peck D, Sweet-Cordero A, Ebert BL, Mak RH, Ferrando AA, et al. MicroRNA expression profiles classify human cancers. Nature. 2005;435(7043):834-8.

30. Calin GA, Ferracin M, Cimmino A, Di Leva G, Shimizu M, Wojcik SE, lorio MV, Visone R, Sever NI, Fabbri M, et al. A MicroRNA signature associated with prognosis and progression in chronic lymphocytic leukemia. N Engl J Med. 2005;353(17):1793-801.

31. Schetter AJ, Leung SY, Sohn JJ, Zanetti KA, Bowman ED, Yanaihara N, Yuen ST, Chan TL, Kwong DL, Au GK, et al. MicroRNA expression profiles associated with prognosis and therapeutic outcome in colon adenocarcinoma. JAMA. 2008;299(4):425-36.

32. Medina PP, Slack FJ. microRNAs and cancer: an overview. Cell Cycle. 2008; 7(16):2485-92.

33. Jung M, Schaefer A, Steiner I, Kempkensteffen C, Stephan C, Erbersdobler A, Jung K. Robust microRNA stability in degraded RNA preparations from human tissue and cell samples. Clin Chem. 2010;56(6):998-1006.

34. Dijkstra JR, Mekenkamp LJ, Teerenstra S, De Krijger I, Nagtegaal ID. MicroRNA expression in formalin-fixed paraffin embedded tissue using real time quantitative PCR: the strengths and pitfalls. J Cell Mol Med. 2012;16(4):683-90. 
35. Mitchell PS, Parkin RK, Kroh EM, Fritz BR, Wyman SK, Pogosova-Agadjanyan EL, Peterson A, Noteboom J, O'Briant KC, Allen A, et al. Circulating microRNAs as stable blood-based markers for cancer detection. Proc Natl Acad Sci U S A. 2008;105(30):10513-8.

36. Chen X, Ba Y, Ma L, Cai X, Yin Y, Wang K, Guo J, Zhang Y, Chen J, Guo X, et al. Characterization of microRNAs in serum: a novel class of biomarkers for diagnosis of cancer and other diseases. Cell Res. 2008;18(10):997-1006.

37. Kong W, Yang H, He L, Zhao JJ, Coppola D, Dalton WS, Cheng JQ. MicroRNA-155 is regulated by the transforming growth factor beta/Smad pathway and contributes to epithelial cell plasticity by targeting RhoA. Mol Cell Biol. 2008;28(22):6773-84.

38. O'Connell RM, Taganov KD, Boldin MP, Cheng G, Baltimore D. MicroRNA-155 is induced during the macrophage inflammatory response. Proc Natl Acad Sci U S A. 2007;104(5):1604-9.

39. Yin Q, McBride J, Fewell C, Lacey M, Wang X, Lin Z, Cameron J, Flemington EK. MicroRNA-155 is an Epstein-Barr virus-induced gene that modulates Epstein-Barr virus-regulated gene expression pathways. J Virol. 2008;82(11): 5295-306.

40. Ambs S, Prueitt RL, Yi M, Hudson RS, Howe TM, Petrocca F, Wallace TA, Liu CG, Volinia S, Calin GA, et al. Genomic profiling of microRNA and messenger RNA reveals deregulated microRNA expression in prostate cancer. Cancer Res. 2008;68(15):6162-70.

41. Galardi S, Mercatelli N, Giorda E, Massalini S, Frajese GV, Ciafre SA, Farace MG. miR-221 and miR-222 expression affects the proliferation potential of human prostate carcinoma cell lines by targeting p27Kip1. J Biol Chem. 2007;282(32):23716-24.

42. Mercatelli N, Coppola V, Bonci D, Miele F, Costantini A, Guadagnoli M, Bonanno E, Muto G, Frajese GV, De Maria R, et al. The inhibition of the highly expressed miR-221 and miR-222 impairs the growth of prostate carcinoma xenografts in mice. PLoS ONE. 2008:3(12):e4029.

43. Sylvestre Y, De Guire V, Querido E, Mukhopadhyay UK, Bourdeau V, Major F, Ferbeyre G, Chartrand P. An E2F/miR-20a autoregulatory feedback loop. J Biol Chem. 2007;282(4):2135-43.

44. He L, Thomson JM, Hemann MT, Hernando-Monge E, Mu D, Goodson S, Powers S, Cordon-Cardo C, Lowe SW, Hannon GJ, et al. A microRNA polycistron as a potential human oncogene. Nature. 2005:435(7043):828-33.

45. Volinia S, Calin GA, Liu CG, Ambs S, Cimmino A, Petrocca F, Visone R, lorio $M$, Roldo C, Ferracin $M$, et al. A microRNA expression signature of human solid tumors defines cancer gene targets. Proc Natl Acad Sci U S A. 2006; 103(7):2257-61.

46. Chang YS, Chen WY, Yin JJ, Sheppard-Tillman H, Huang J, Liu YN. EGF receptor promotes prostate cancer bone metastasis by downregulating miR-1 and activating TWIST1. Cancer Res. 2015;75(15):3077-86.

47. Kojima S, Chiyomaru T, Kawakami K, Yoshino H, Enokida H, Nohata N, Fuse M, Ichikawa T, Naya Y, Nakagawa M, et al. Tumour suppressors miR-1 and miR-133a target the oncogenic function of purine nucleoside phosphorylase (PNP) in prostate cancer. Br J Cancer. 2012;106(2):405-13.

48. Martens-Uzunova ES, Jalava SE, Dits NF, van Leenders GJ, Moller S, Trapman J, Bangma CH, Litman T, Visakorpi T, Jenster G. Diagnostic and prognostic signatures from the small non-coding RNA transcriptome in prostate cancer. Oncogene. 2012;31(8):978-91.

49. Hudson RS, Yi M, Esposito D, Watkins SK, Hurwitz AA, Yfantis HG, Lee DH, Borin JF, Naslund MJ, Alexander RB, et al. MicroRNA-1 is a candidate tumor suppressor and prognostic marker in human prostate cancer. Nucleic Acids Res. 2012;40(8):3689-703.

50. Liu YN, Yin JJ, Abou-Kheir W, Hynes PG, Casey OM, Fang L, Yi M, Stephens RM, Seng V, Sheppard-Tillman H, et al. MiR-1 and miR-200 inhibit EMT via Slug-dependent and tumorigenesis via Slug-independent mechanisms. Oncogene. 2013;32(3):296-306.

51. Karatas OF, Guzel E, Suer I, Ekici ID, Caskurlu T, Creighton CJ, Ittmann M, Ozen M. miR-1 and miR-133b are differentially expressed in patients with recurrent prostate cancer. PLoS One. 2014;9(6):e98675.

52. Stope MB, Stender $C$, Schubert T, Peters $S$, Weiss M, Ziegler P, Zimmermann $U$, Walther R, Burchardt M. Heat-shock protein HSPB1 attenuates microRNA miR-1 expression thereby restoring oncogenic pathways in prostate cancer cells. Anticancer Res. 2014;34(7):3475-80.

53. Liu YN, Yin J, Barrett B, Sheppard-Tillman H, Li D, Casey OM, Fang L, Hynes PG, Ameri AH, Kelly K. Loss of androgen-regulated MicroRNA 1 activates SRC and promotes prostate cancer bone metastasis. Mol Cell Biol. 2015;35(11): 1940-51.
54. Yaman Agaoglu F, Kovancilar M, Dizdar Y, Darendeliler E, Holdenrieder S, Dalay N, Gezer U. Investigation of miR-21, miR-141, and miR-221 in blood circulation of patients with prostate cancer. Tumour Biol. 2011; 32(3):583-8.

55. Li T, Li RS, Li YH, Zhong S, Chen YY, Zhang CM, Hu MM, Shen ZJ. miR-21 as an independent biochemical recurrence predictor and potential therapeutic target for prostate cancer. J Urol. 2012;187(4):1466-72.

56. Shen J, Hruby GW, McKiernan JM, Gurvich I, Lipsky MJ, Benson MC, Santella RM. Dysregulation of circulating microRNAs and prediction of aggressive prostate cancer. Prostate. 2012;72(13):1469-77.

57. Ribas J, Ni X, Haffner M, Wentzel EA, Salmasi AH, Chowdhury WH, Kudrolli TA, Yegnasubramanian S, Luo J, Rodriguez R, et al. miR-21: an androgen receptor-regulated microRNA that promotes hormone-dependent and hormone-independent prostate cancer growth. Cancer Res. 2009;69(18): 7165-9.

58. Reis ST, Pontes-Junior J, Antunes AA, Dall'Oglio MF, Dip N, Passerotti CC, Rossini GA, Morais DR, Nesrallah AJ, Piantino C, et al. miR-21 may acts as an oncomir by targeting RECK, a matrix metalloproteinase regulator, in prostate cancer. BMC Urol. 2012:12:14

59. Mishra S, Deng JJ, Gowda PS, Rao MK, Lin CL, Chen CL, Huang T, Sun LZ. Androgen receptor and microRNA-21 axis downregulates transforming growth factor beta receptor II (TGFBR2) expression in prostate cancer. Oncogene. 2014;33(31):4097-106.

60. Li T, Li D, Sha J, Sun P, Huang Y. MicroRNA-21 directly targets MARCKS and promotes apoptosis resistance and invasion in prostate cancer cells. Biochem Biophys Res Commun. 2009;383(3):280-5.

61. Szczyrba J, Loprich E, Wach S, Jung V, Unteregger G, Barth S, Grobholz R, Wieland W, Stohr R, Hartmann A, et al. The microRNA profile of prostate carcinoma obtained by deep sequencing. Mol Cancer Res. 2010;8(4):529-38.

62. Poliseno L, Salmena L, Riccardi L, Fornari A, Song MS, Hobbs RM, Sportoletti P, Varmeh S, Egia A, Fedele G, et al. Identification of the miR-106b 25 microRNA cluster as a proto-oncogenic PTEN-targeting intron that cooperates with its host gene MCM7 in transformation. Sci Signal. 2010; 3(117):ra29.

63. Hudson RS, Yi M, Esposito D, Glynn SA, Starks AM, Yang Y, Schetter AJ, Watkins SK, Hurwitz AA, Dorsey TH, et al. MicroRNA-106b-25 cluster expression is associated with early disease recurrence and targets caspase-7 and focal adhesion in human prostate cancer. Oncogene. 2013;32(35):4139-47.

64. Liang H, Studach L, Hullinger RL, Xie J, Andrisani OM. Down-regulation of RE-1 silencing transcription factor (REST) in advanced prostate cancer by hypoxia-induced miR-106b 25. Exp Cell Res. 2014;320(2):188-99.

65. DeVere White RW, Vinall RL, Tepper CG, Shi XB. MicroRNAs and their potential for translation in prostate cancer. Urol Oncol. 2009;27(3):307-11.

66. Shi XB, Xue L, Yang J, Ma AH, Zhao J, Xu M, Tepper CG, Evans CP, Kung HJ, deVere White RW. An androgen-regulated miRNA suppresses Bak1 expression and induces androgen-independent growth of prostate cancer cells. Proc Natl Acad Sci U S A. 2007;104(50):19983-8.

67. Bonci D, Coppola V, Musumeci M, Addario A, Giuffrida R, Memeo L, D'Urso L, Pagliuca A, Biffoni M, Labbaye C, et al. The miR-15a-miR-16-1 cluster controls prostate cancer by targeting multiple oncogenic activities. Nat Med. 2008; 14(11):1271-7

68. Aqeilan Rl, Calin GA, Croce CM. miR-15a and miR-16-1 in cancer: discovery, function and future perspectives. Cell Death Differ. 2010;17(2):215-20.

69. Varambally S, Cao Q, Mani RS, Shankar S, Wang X, Ateeq B, Laxman B, Cao X, Jing X, Ramnarayanan K, et al. Genomic loss of microRNA-101 leads to overexpression of histone methyltransferase EZH2 in cancer. Science. 2008;322(5908):1695-9.

70. Musiyenko A, Bitko V, Barik S. Ectopic expression of miR-126*, an intronic product of the vascular endothelial EGF-like 7 gene, regulates prostein translation and invasiveness of prostate cancer LNCaP cells. J Mol Med (Berl). 2008;86(3):313-22.

71. Fujita Y, Kojima K, Hamada N, Ohhashi R, Akao Y, Nozawa Y, Deguchi T, Ito M. Effects of miR-34a on cell growth and chemoresistance in prostate cancer PC3 cells. Biochem Biophys Res Commun. 2008;377(1):114-9.

72. Lodygin D, Tarasov V, Epanchintsev A, Berking C, Knyazeva T, Korner H, Knyazev P, Diebold J, Hermeking H. Inactivation of miR-34a by aberrant CpG methylation in multiple types of cancer. Cell Cycle. 2008;7(16):2591-600.

73. Lin SL, Chiang A, Chang D, Ying SY. Loss of mir-146a function in hormonerefractory prostate cancer. RNA. 2008;14(3):417-24. 
74. Fuse M, Nohata N, Kojima S, Sakamoto S, Chiyomaru T, Kawakami K, Enokida H, Nakagawa M, Naya Y, Ichikawa T, et al. Restoration of miR-145 expression suppresses cell proliferation, migration and invasion in prostate cancer by targeting FSCN1. Int J Oncol. 2011;38(4):1093-101.

75. Suh SO, Chen Y, Zaman MS, Hirata H, Yamamura S, Shahryari V, Liu J, Tabatabai ZL, Kakar S, Deng G, et al. MicroRNA-145 is regulated by DNA methylation and p53 gene mutation in prostate cancer. Carcinogenesis. 2011;32(5):772-8.

76. Tong AW, Fulgham P, Jay C, Chen P, Khalil I, Liu S, Senzer N, Eklund AC, Han J, Nemunaitis J. MicroRNA profile analysis of human prostate cancers. Cancer Gene Ther. 2009;16(3):206-16.

77. Wach S, Nolte E, Szczyrba J, Stohr R, Hartmann A, Orntoft T, Dyrskjot L, Eltze E, Wieland W, Keck B et al. MicroRNA profiles of prostate carcinoma detected by multiplatform microRNA screening. Int J Cancer 2012;130(3):611-21.

78. Gandellini P, Folini M, Longoni N, Pennati M, Binda M, Colecchia M, Salvioni R, Supino R, Moretti R, Limonta P, et al. miR-205 exerts tumor-suppressive functions in human prostate through down-regulation of protein kinase cepsilon. Cancer Res. 2009;69(6):2287-95.

79. Ozen M, Creighton CJ, Ozdemir M, Ittmann M. Widespread deregulation of microRNA expression in human prostate cancer. Oncogene. 2008;27(12): 1788-93.

80. Prueitt RL, Yi M, Hudson RS, Wallace TA, Howe TM, Yfantis HG, Lee DH, Stephens RM, Liu CG, Calin GA, et al. Expression of microRNAs and proteincoding genes associated with perineural invasion in prostate cancer. Prostate. 2008:68(11):1152-64.

81. Schaefer A, Jung M, Mollenkopf HJ, Wagner I, Stephan C, Jentzmik F, Miller K, Lein M, Kristiansen G, Jung K. Diagnostic and prognostic implications of microRNA profiling in prostate carcinoma. Int J Cancer. 2010;126(5):1166-76.

82. Yang K, Handorean AM, Iczkowski KA. MicroRNAs 373 and 520c are downregulated in prostate cancer, suppress CD44 translation and enhance invasion of prostate cancer cells in vitro. Int J Clin Exp Pathol. 2009;2(4):361-9.

83. Patron JP, Fendler A, Bild M, Jung U, Muller $H$, Arntzen MO, Piso C, Stephan C, Thiede B, Mollenkopf HJ, et al. MiR-133b targets antiapoptotic genes and enhances death receptor-induced apoptosis. PLoS ONE. 2012;7(4):e35345.

84. Li X, Wan X, Chen H, Yang S, Liu Y, Mo W, Meng D, Du W, Huang Y, Wu H, et al. Identification of miR-133b and RB1CC1 as independent predictors for biochemical recurrence and potential therapeutic targets for prostate cancer. Clin Cancer Res. 2014;20(9):2312-25.

85. Costa-Pinheiro P, Ramalho-Carvalho J, Vieira FQ, Torres-Ferreira J, Oliveira J, Goncalves CS, Costa BM, Henrique R, Jeronimo C. MicroRNA375 plays a dual role in prostate carcinogenesis. Clin Epigenetics. 2015; 7(1):42.

86. Gandellini P, Folini M, Zaffaroni N. Towards the definition of prostate cancer-related microRNAs: where are we now? Trends Mol Med. 2009;15(9): 381-90

87. Porkka KP, Pfeiffer MJ, Waltering KK, Vessella RL, Tammela TL, Visakorpi $T$. MicroRNA expression profiling in prostate cancer. Cancer Res. 2007:67(13): 6130-5

88. Khan AP, Poisson LM, Bhat VB, Fermin D, Zhao R, Kalyana-Sundaram S, Michailidis G, Nesvizhskii Al, Omenn GS, Chinnaiyan AM, et al. Quantitative proteomic profiling of prostate cancer reveals a role for miR-128 in prostate cancer. Mol Cell Proteomics. 2010;9(2):298-312.

89. Kristensen H, Haldrup C, Strand S, Mundbjerg K, Mortensen MM, Thorsen K, Ostenfeld MS, Wild PJ, Arsov C, Goering W, et al. Hypermethylation of the GABRE $\sim$ miR-452 miR-224 promoter in prostate cancer predicts biochemical recurrence after radical prostatectomy. Clin Cancer Res. 2014; 20(8):2169-81.

90. Wang L, Tang H, Thayanithy V, Subramanian S, Oberg AL, Cunningham JM Cerhan JR, Steer CJ, Thibodeau SN. Gene networks and microRNAs implicated in aggressive prostate cancer. Cancer Res. 2009;69(24):9490-7.

91. Spahn M, Kneitz S, Scholz CJ, Stenger N, Rudiger T, Strobel P, Riedmiller H, Kneitz B. Expression of microRNA-221 is progressively reduced in aggressive prostate cancer and metastasis and predicts clinical recurrence. Int J Cancer. 2010;127(2):394-403.

92. Hagman Z, Larne O, Edsjo A, Bjartell A, Ehrnstrom RA, Ulmert D, Lilja $H$, Ceder Y. miR-34c is downregulated in prostate cancer and exerts tumor suppressive functions. Int J Cancer. 2010;127(12):2768-76.

93. Pesta M, Klecka J, Kulda V, Topolcan O, Hora M, Eret V, Ludvikova M, Babjuk M, Novak K, Stolz J, et al. Importance of miR-20a expression in prostate cancer tissue. Anticancer Res. 2010;30(9):3579-83.
94. Taylor BS, Schultz N, Hieronymus H, Gopalan A, Xiao Y, Carver BS, Arora VK, Kaushik $\mathrm{P}$, Cerami E, Reva B, et al. Integrative genomic profiling of human prostate cancer. Cancer Cell. 2010;18(1):11-22.

95. Hao Y, Zhao Y, Zhao X, He C, Pang X, Wu TC, Califano JA, Gu X. Improvement of prostate cancer detection by integrating the PSA test with miRNA expression profiling. Cancer Invest. 2011;29(4):318-24.

96. Mishra S, Lin CL, Huang TH, Bouamar H, Sun LZ. MicroRNA-21 inhibits p57Kip2 expression in prostate cancer. Mol Cancer. 2014;13:212.

97. Bonci D, Coppola V, Patrizii M, Addario A, Cannistraci A, Francescangeli F, Pecci R, Muto G, Collura D, Bedini R, et al. A microRNA code for prostate cancer metastasis. Oncogene. 2016;35(9):1180-92.

98. Mihelich BL, Khramtsova EA, Arva N, Vaishnav A, Johnson DN, Giangreco AA Martens-Uzunova E, Bagasra O, Kajdacsy-Balla A, Nonn L. miR-183-96-182 cluster is overexpressed in prostate tissue and regulates zinc homeostasis in prostate cells. J Biol Chem. 2011;286(52):44503-11.

99. Moltzahn F, Olshen AB, Baehner L, Peek A, Fong L, Stoppler $H$, Simko J, Hilton JF, Carroll P, Blelloch R. Microfluidic-based multiplex qRT-PCR identifies diagnostic and prognostic microRNA signatures in the sera of prostate cancer patients. Cancer Res. 2011;71(2): 550-60.

100. Zhang HL, Yang LF, Zhu Y, Yao XD, Zhang SL, Dai B, Zhu YP, Shen YJ, Shi GH, Ye DW. Serum miRNA-21: elevated levels in patients with metastatic hormone-refractory prostate cancer and potential predictive factor for the efficacy of docetaxel-based chemotherapy. Prostate. 2011; 71(3):326-31.

101. Avgeris M, Stravodimos K, Fragoulis EG, Scorilas A. The loss of the tumoursuppressor miR-145 results in the shorter disease-free survival of prostate cancer patients. Br J Cancer. 2013;108(12):2573-81.

102. Amankwah EK, Anegbe E, Park H, Pow-Sang J, Hakam A, Park JY. miR-21, miR-221 and miR-222 expression and prostate cancer recurrence among obese and non-obese cases. Asian J Androl. 2013;15(2):226-30.

103. Barnabas N, Xu L, Savera A, Hou Z, Barrack ER. Chromosome 8 markers of metastatic prostate cancer in African American men: gain of the MIR151 gene and loss of the NKX3-1 gene. Prostate. 2011;71(8):857-71.

104. Leite KR, Tomiyama A, Reis ST, Sousa-Canavez JM, Sanudo A, Camara-Lopes $\mathrm{LH}$, Srougi M. MicroRNA expression profiles in the progression of prostate cancer-from high-grade prostate intraepithelial neoplasia to metastasis. Urol Oncol. 2013;31(6):796-801.

105. Srivastava A, Goldberger H, Dimtchev A, Ramalinga M, Chijioke J, Marian C, Oermann EK, Uhm S, Kim JS, Chen LN, et al. MicroRNA profiling in prostate cancer-the diagnostic potential of urinary miR-205 and miR-214. PLOS ONE. 2013;8(10):e76994.

106. Tsuchiyama K, Ito H, Taga M, Naganuma S, Oshinoya Y, Nagano K, Yokoyama O, Itoh H. Expression of microRNAs associated with Gleason grading system in prostate cancer: miR-182-5p is a useful marker for high grade prostate cancer. Prostate. 2013;73(8):827-34.

107. Guzel E, Karatas OF, Semercioz A, Ekici S, Aykan S, Yentur S, Creighton CJ, Ittmann M, Ozen M. Identification of microRNAs differentially expressed in prostatic secretions of patients with prostate cancer. Int J Cancer. 2015; 136(4):875-9.

108. Larne O, Martens-Uzunova E, Hagman Z, Edsjo A, Lippolis G, den Berg MS, Bjartell A, Jenster G, Ceder Y. miQ-a novel microRNA based diagnostic and prognostic tool for prostate cancer. Int J Cancer. 2013; 132(12):2867-75.

109. Mavridis K, Stravodimos K, Scorilas A. Downregulation and prognostic performance of microRNA 224 expression in prostate cancer. Clin Chem. 2013;59(1):261-9.

110. Walter BA, Valera VA, Pinto PA, Merino MJ. Comprehensive microRNA profiling of prostate cancer. J Cancer. 2013;4(5):350-7.

111. Casanova-Salas I, Rubio-Briones J, Calatrava A, Mancarella C, Masia E, Casanova J, Fernandez-Serra A, Rubio L, Ramirez-Backhaus M, Arminan A, et al. Identification of miR-187 and miR-182 as biomarkers of early diagnosis and prognosis in patients with prostate cancer treated with radical prostatectomy. J Urol. 2014;192:252-9.

112. Kristensen $H$, Thomsen AR, Haldrup C, Dyrskjot L, Hoyer S, Borre M, Mouritzen P, Orntoft TF, Sorensen KD. Novel diagnostic and prognostic classifiers for prostate cancer identified by genome-wide microRNA profiling. Oncotarget. 2016;7:30760-71.

113. Haldrup C, Kosaka N, Ochiya T, Borre M, Hoyer S, Orntoft TF, Sorensen KD. Profiling of circulating microRNAs for prostate cancer biomarker discovery. Drug Deliv Transl Res. 2014;4(1):19-30. 
114. Selth LA, Townley S, Gillis JL, Ochnik AM, Murti K, Macfarlane RJ, Chi KN, Marshall VR, Tilley WD, Butler LM. Discovery of circulating microRNAs associated with human prostate cancer using a mouse model of disease. Int J Cancer. 2012;131(3):652-61.

115. Brase JC, Johannes M, Schlomm T, Falth M, Haese A, Steuber T, Beissbarth T, Kuner $\mathrm{R}$, Sultmann $\mathrm{H}$. Circulating miRNAs are correlated with tumor progression in prostate cancer. Int J Cancer. 2011;128(3):608-16.

116. Nguyen HC, Xie W, Yang M, Hsieh CL, Drouin S, Lee GS, Kantoff PW. Expression differences of circulating microRNAs in metastatic castration resistant prostate cancer and low-risk, localized prostate cancer. Prostate. 2013;73(4):346-54.

117. Bryant RJ, Pawlowski T, Catto JW, Marsden G, Vessella RL, Rhees B, Kuslich C, Visakorpi T, Hamdy FC. Changes in circulating microRNA levels associated with prostate cancer. Br J Cancer. 2012;106(4):768-74

118. Mahn R, Heukamp LC, Rogenhofer S, von Ruecker A, Muller SC, Ellinger J. Circulating microRNAs (miRNA) in serum of patients with prostate cancer. Urology. 2011;77(5):1265. e1269-1216.

119. Chen ZH, Zhang GL, Li HR, Luo JD, Li ZX, Chen GM, Yang J. A panel of five circulating microRNAs as potential biomarkers for prostate cancer. Prostate. 2012;72(13):1443-52.

120. Cheng HH, Mitchell PS, Kroh EM, Dowell AE, Chery L, Siddiqui J, Nelson PS, Vessella RL, Knudsen BS, Chinnaiyan AM, et al. Circulating microRNA profiling identifies a subset of metastatic prostate cancer patients with evidence of cancer-associated hypoxia. PLoS ONE. 2013;8(7):e69239.

121. Westermann AM, Schmidt D, Holdenrieder S, Moritz R, Semjonow A, Schmidt M, Kristiansen G, Muller SC, Ellinger J. Serum microRNAs as biomarkers in patients undergoing prostate biopsy: results from a prospective multi-center study. Anticancer Res. 2014;34(2):665-9.

122. Kachakova D, Mitkova A, Popov E, Popov I, Vlahova A, Dikov T, Christova S, Mitev V, Slavov C, Kaneva R. Combinations of serum prostate-specific antigen and plasma expression levels of let-7c, miR-30c, miR-141, and miR-375 as potential better diagnostic biomarkers for prostate cancer. DNA Cell Biol. 2015;34(3):189-200.

123. Watahiki A, Macfarlane RJ, Gleave ME, Crea F, Wang Y, Helgason CD, Chi KN. Plasma miRNAs as biomarkers to identify patients with castration-resistant metastatic prostate cancer. Int J Mol Sci. 2013;14(4):7757-70.

124. Wang SY, Shiboski S, Belair CD, Cooperberg MR, Simko JP, Stoppler H, Cowan J, Carroll PR, Blelloch R. miR-19, miR-345, miR-519c-5p serum levels predict adverse pathology in prostate cancer patients eligible for active surveillance. PLoS ONE. 2014;9(6):e98597.

125. Mihelich BL, Maranville JC, Nolley R, Peehl DM, Nonn L. Elevated serum microRNA levels associate with absence of high-grade prostate cancer in a retrospective cohort. PLOS ONE. 2015;10(4):e0124245.

126. Haj-Ahmad TA, Abdalla MA, Haj-Ahmad Y. Potential urinary miRNA biomarker candidates for the accurate detection of prostate cancer among benign prostatic hyperplasia patients. J Cancer. 2014;5(3):182-91.

127. Korzeniewski N, Tosev G, Pahernik S, Hadaschik B, Hohenfellner M, Duensing S. Identification of cell-free microRNAs in the urine of patients with prostate cancer. Urol Oncol. 2015;33(1):16. e17-22.

128. Roberts MJ, Chow CW, Schirra HJ, Richards R, Buck M, Selth LA, Doi SA, Samaratunga $H$, Perry-Keene J, Payton D, et al. Diagnostic performance of expression of PCA3, Hepsin and miR biomarkers inejaculate in combination with serum PSA for the detection of prostate cancer. Prostate. 2015;75(5): 539-49.

129. Elmen J, Lindow M, Silahtaroglu $A$, Bak M, Christensen $M$, Lind-Thomsen $A$, Hedtjarn M, Hansen JB, Hansen HF, Straarup EM, et al. Antagonism of microRNA-122 in mice by systemically administered LNA-antimiR leads to up-regulation of a large set of predicted target mRNAs in the liver. Nucleic Acids Res. 2008;36(4):1153-62.

130. Krutzfeldt J, Rajewsky N, Braich R, Rajeev KG, Tuschl T, Manoharan M, Stoffel M. Silencing of microRNAs in vivo with 'antagomirs'. Nature. 2005;438(7068): 685-9.

131. Stenvang J, Kauppinen S. MicroRNAs as targets for antisense-based therapeutics. Expert Opin Biol Ther. 2008:8(1):59-81.

132. Sun T, Wang Q, Balk S, Brown M, Lee GS, Kantoff $P$. The role of microRNA221 and microRNA-222 in androgen-independent prostate cancer cell lines. Cancer Res. 2009:69(8):3356-63.
133. Gonzales JC, Fink LM, Goodman Jr OB, Symanowski JT, Vogelzang NJ, Ward DC. Comparison of circulating MicroRNA 141 to circulating tumor cells, lactate dehydrogenase, and prostate-specific antigen for determining treatment response in patients with metastatic prostate cancer. Clin Genitourin Cancer. 2011;9(1):39-45.

134. He HC, Han ZD, Dai QS, Ling XH, Fu X, Lin ZY, Deng YH, Qin GQ, Cai C, Chen $\mathrm{JH}$, et al. Global analysis of the differentially expressed miRNAs of prostate cancer in Chinese patients. BMC Genomics. 2013;14:757.

135. Lichner Z, Fendler A, Saleh C, Nasser AN, Boles D, Al-Haddad S, Kupchak P, Dharsee $M$, Nuin PS, Evans KR, et al. MicroRNA signature helps distinguish early from late biochemical failure in prostate cancer. Clin Chem. 2013; 59(11):1595-603.

136. Someya M, Yamamoto H, Nojima M, Hori M, Tateoka K, Nakata K, Takagi M, Saito M, Hirokawa N, Tokino T, et al. Relation between Ku80 and microRNA99a expression and late rectal bleeding after radiotherapy for prostate cancer. Radiother Oncol. 2015;115(2):235-9.

137. Lodes MJ, Caraballo M, Suciu D, Munro S, Kumar A, Anderson B. Detection of cancer with serum miRNAs on an oligonucleotide microarray. PLoS ONE. 2009:4(7):e6229.

138. Leite KR, Tomiyama A, Reis ST, Sousa-Canavez JM, Sanudo A, Dall'Oglio MF, Camara-Lopes LH, Srougi M. MicroRNA-100 expression is independently related to biochemical recurrence of prostate cancer. J Urol. 2011;185(3): $1118-22$.

139. Dip N, Reis ST, Abe DK, Viana NI, Morais DR, Moura CM, Katz B, Silva IA, Srougi M, Leite KR. Micro RNA expression and prognosis in low-grade non-invasive urothelial carcinoma. Int Braz J Urol. 2014:40(5):644-9.

\section{Submit your next manuscript to BioMed Central and we will help you at every step:}

- We accept pre-submission inquiries

- Our selector tool helps you to find the most relevant journal

- We provide round the clock customer support

- Convenient online submission

- Thorough peer review

- Inclusion in PubMed and all major indexing services

- Maximum visibility for your research

Submit your manuscript at www.biomedcentral.com/submit
) Biomed Central 